Louisiana State University

LSU Digital Commons

\title{
Silica-Conjugated Polymer Hybrid Fluorescent Nanoparticles: Preparation by Surface-Initiated Polymerization and Spectroscopic Studies
}

\author{
Sourav Chatterjee \\ Louisiana State University \\ Tony E. Karam \\ Louisiana State University \\ Cornelia Rosu \\ Georgia Institute of Technology \\ Chun Han Wang \\ Louisiana State University \\ Sang Gil Youm \\ Louisiana State University
}

See next page for additional authors

Follow this and additional works at: https://digitalcommons.Isu.edu/chemistry_pubs

\section{Recommended Citation}

Chatterjee, S., Karam, T., Rosu, C., Wang, C., Youm, S., Li, X., Do, C., Losovyj, Y., Russo, P., Haber, L., \& Nesterov, E. (2018). Silica-Conjugated Polymer Hybrid Fluorescent Nanoparticles: Preparation by SurfaceInitiated Polymerization and Spectroscopic Studies. Journal of Physical Chemistry C, 122 (12), 6963-6975. https://doi.org/10.1021/acs.jpcc.8b00313

This Article is brought to you for free and open access by the Department of Chemistry at LSU Digital Commons. It has been accepted for inclusion in Faculty Publications by an authorized administrator of LSU Digital Commons. For more information, please contact ir@lsu.edu. 


\section{Authors}

Sourav Chatterjee, Tony E. Karam, Cornelia Rosu, Chun Han Wang, Sang Gil Youm, Xin Li, Changwoo Do, Yaroslav Losovyj, Paul S. Russo, Louis H. Haber, and Evgueni E. Nesterov 


\section{Notice of Copyright}

This manuscript has been authored by UT-Battelle, LLC under Contract No. DE-AC05-000R22725 with the U.S. Department of Energy. The United States Government retains and the publisher, by accepting the article for publication, acknowledges that the United States Government retains a non-exclusive, paid-up, irrevocable, world-wide license to publish or reproduce the published form of this manuscript, or allow others to do so, for United States Government purposes. The Department of Energy will provide public access to these results of federally sponsored research in accordance with the DOE Public Access Plan (http://energy.gov/downloads/doe-public-accessplan). 


\section{Silica - Conjugated Polymer Hybrid Fluorescent}

\section{Nanoparticles: Preparation by Surface-Initiated}

\section{Polymerization and Spectroscopic Studies}

Sourav Chatterjee, ${ }^{\dagger}$ Tony E. Karam, ${ }^{\dagger}$ Cornelia Rosu,,${ }^{\dagger}$ Chun-Han Wang, ${ }^{\dagger}$ Sang Gil Youm, ${ }^{\dagger}$ Xin Li,${ }^{\dagger}$

Changwoo Do, ${ }^{\S}$ Yaroslav Losovyj, ${ }^{\prime}$ Paul S. Russo, ${ }^{\not}$ Louis H. Haber,${ }^{\dagger}$ and Evgueni E. Nesterov ${ }^{*}, \dot{ }$

'Department of Chemistry, Louisiana State University, Baton Rouge, Louisiana 70803, United States

School of Materials Science and Engineering, Georgia Institute of Technology, Atlanta, Georgia 30332, United States

§Spallation Neutron Source, Oak Ridge National Laboratory, Oak Ridge, Tennessee 37831, Unites States

'Department of Chemistry, Indiana University, Bloomington, Indiana 47401, United States

\section{RECEIVED DATE (to be automatically inserted after your manuscript is accepted)}

ABSTRACT. Organic/inorganic hybrid nanoscale materials possess fascinating optical, electronic, magnetic and catalytic properties which are promising for a variety of practical applications. Such properties can be dramatically affected by the hierarchical structure and molecular organization in the nanomaterials. Herein, we employed surface-initiated Kumada catalyst-transfer polymerization to prepare hybrid materials consisting of shells of conjugated polymers, polythiophene or poly( $p$ phenylene), and their block copolymers covalently attached to the surface of silica nanoparticles. Due to the controlled chain-growth mechanism of surface-initiated polymerization, we obtained structural 
differentiation between two conjugated polymer blocks in the diblock copolymer shells, which resulted in distinct spectroscopic properties related to intra-particle excitation energy transfer between the nanoscale polymer shell components, as well as formation of the interfacial exciplex states. The spectroscopic phenomena were further understood via time-resolved transient absorption spectroscopy studies. Overall, the surface-initiated polymerization provided an efficient tool to prepare structurally defined and highly stable organic polymer shell - inorganic core nanoparticles with tunable spectroscopic characteristics not achievable from corresponding single-component systems. 


\section{Introduction}

Recent advances in materials science have enabled design of nanomaterials with tunable photophysical characteristics stemming from the enhanced surface-to-volume ratio and the nanoscale confinement effect, contrasting them to similar bulk materials. Such nanomaterials with controlled size and structural features are particularly suitable for the development of sensory devices, ${ }^{1-4}$ photovoltaic, ${ }^{5,6}$ optoelectronic, ${ }^{7,8}$ and biomedical applications. ${ }^{9-11}$

Organic/inorganic hybrid nanomaterials possess a unique combination of optical, electronic, magnetic and catalytic properties stemming from both inorganic and organic components. ${ }^{12-15}$ Typical hybrid materials consist of an inorganic core with an attached polymer shell. Hybrid nanoscale systems provide extensive opportunities for the development of new materials with physical and chemical characteristics unattainable with their single-component counterparts. Among organic materials used in the design of hybrid nanomaterials, conjugated polymers (CPs) are particularly well suited for tuning and modification of the materials' photophysical characteristics. ${ }^{16-22}$ CPs are a class of polymers which possess an extensive $\pi$-electron delocalization along the polymer backbone and typically display large extinction coefficients for light absorption and, in many cases, show strong fluorescence. In the condensed state (such as in thin films), they exhibit complex self-organization driven by entropy and a multitude of weak intermolecular interactions, which often leads to poorly defined mesoscale structure and morphology and complex and not well understood spectroscopic characteristics stemming from intermolecular electronic interactions and chain aggregation. Controlled or directed mesoscale organization of CPs thus remains a challenge and requires availability of synthetic methods capable of producing hierarchically organized polymer structures.

Hybrid nanoparticles represent the largest subclass of nanoscale materials and can be prepared either by physical adsorption of polymer shell or by using covalent grafting techniques such as grafting to or grafting from approaches. ${ }^{23,} 24$ In the grafting to approach, the organic shell is formed by chemically attaching pre-synthesized polymers to the inorganic nanoparticle surface. It offers a 
convenient way to link end-functionalized polymers to a complementary functionalized inorganic nanoscale surface. ${ }^{25-30}$ Despite its simplicity, the grafting to approach typically results in low grafting density, due to entropic limitations imposed on the reactivity of the end-functionalized polymer chains.

Surface-initiated (also called surface-confined) polymerization, or the grafting from approach, is a versatile technique to prepare "hairy" particles with a variable molecular composition of the polymer shell. ${ }^{23,24}$ In contrast to the grafting to approach, it does not require pre-synthesized end-functionalized polymers; instead the surface-immobilized polymer chains are prepared directly by monomer polymerization starting from a surface-attached polymerization initiator. This provides better control over the molecular composition and thickness of the polymer brushes, requires no addition of solubilizing groups to the polymer chain, and enables achieving higher grafting density. In the earlier approaches, adding surface-confined polymer shells relied on step-growth polymerization methods (sometimes referred to as grafting through approach) as well as oxidative chemical polymerization. ${ }^{31-36}$ More recently developed grafting from approaches were based on the controlled chain-growth polymerization, and resulted in significant improvement in both the efficiency of the polymerization and control over the molecular composition. ${ }^{23,37-39}$

Scheme 1. Preparation of Ni(II) external catalytic initiator and its use in the synthesis of regioregular poly(3-alkylthiophene)s by controlled chain-growth Kumada catalyst-transfer polymerization.

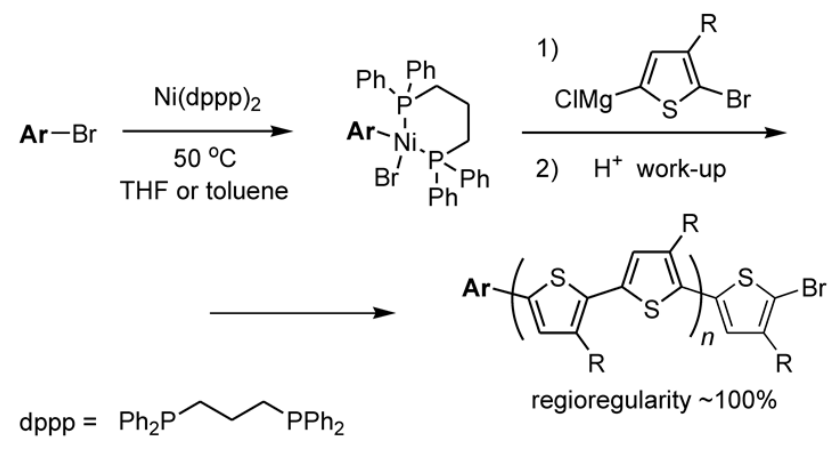

One of the powerful controlled chain-growth polymerization methods to prepare surfaceconfined CPs utilizes Kumada catalyst-transfer polymerization (KCTP). Based on the McCullough and 
Yokozawa discovery of the chain-growth mechanism in the case of formation of poly(3-hexylthiophene) (P3HT), ${ }^{40-43}$ and subsequent design by Kiriy and Luscombe of the externally initiated version of $\mathrm{KCTP},{ }^{44-46}$ it was used by Kiriy, ${ }^{47-50}$ Locklin, ${ }^{51-53}$ and others ${ }^{20,} 54$ to develop CP thin film preparation methods via the grafting from approach. The surface-confined CP thin films obtained by using this method demonstrated high structural stability and unique electronic characteristics related to specific and well-controlled CP molecular organization in the films. Recently, we developed a simple and reliable method to prepare stable external catalytic initiators of KCTP which deliver conjugated polymers and block copolymers with a high degree of molecular and structural control. ${ }^{55}$ In this method, the Ni(II) external catalytic initiators are prepared by the reaction of a suitable aryl halide (bromide or iodide) with readily available $\mathrm{Ni}(0)$ complex $\mathrm{Ni}(\mathrm{dppp})_{2}$ (Scheme 1$)$. Covalent immobilization of a monolayer of such Ni(II) initiators on a surface followed by surface-initiated polymerization enabled preparation of grafted CP thin films (such as polythiophene or poly(p-phenylene)). The detailed structural investigation of the resulting surface-confined polythiophene (PT) thin films revealed formation of the surface domains with crystalline packed PT chains showing uniform molecular organization and alignment within each domain. ${ }^{56}$

The experimental simplicity of the preparation of surface-confined monolayers of Ni(II) catalytic initiators of KCTP and the efficiency of the surface-initiated polymerization prompted us to systematically investigate preparation of hybrid nanoparticles based on surface-attached conjugated polymers and block copolymers. Silica nanoparticles were chosen as the inorganic "core" and unsubstituted polythiophene (PT) and poly(p-phenylene) (PPP) were selected for the organic "shells". Monodisperse silica nanoparticles were chosen since they tend to assemble into ordered closely packed arrays, potentially suitable for various photonic and optoelectronic applications. ${ }^{57,58}$ We hypothesized that stable, covalently linked and molecularly well-defined fluorescent $\mathrm{CP}$ shells attached to the nanoscale sized core would demonstrate unusual spectroscopic and photophysical characteristics not obtainable with bulk materials, and that such characteristics would be tunable via simple structural 
manipulations of the polymer shell, to facilitate the potential applications of these hybrid nanoparticles in optoelectronic devices and biomedical imaging. We also wanted to investigate the effect of nanoscale confinement on the molecular organization and spectroscopic properties of the CPs. Importantly, due to insulating and UV/vis spectroscopically transparent nature of silica core, such hybrid nanoparticles could be an excellent model to help in understanding complex photophysical properties of hybrid nanoscale systems based on semiconducting and/or luminescent cores (e.g. $\mathrm{TiO}_{2}$, quantum dots, etc.) and CP shells. ${ }^{17,20,25-30,35,39,54}$ This paper describes preparation and detailed structural characterization of silica-CP hybrid fluorescent nanoparticles, and their extensive steady-state and time-resolved spectroscopic studies.

\section{Results and Discussion}

\section{Synthesis and structural characterization of conjugated polymer-grafted silica}

nanoparticles. Monodisperse silica nanoparticles were prepared via a modified Stöber process. ${ }^{59,60}$ FT-IR spectroscopy confirmed that the particles had free hydroxyl groups on their surface by showing characteristic band at $945 \mathrm{~cm}^{-1}\left(\mathrm{Si}-\mathrm{OH}\right.$ bending), and a broad band between 3000 and $3700 \mathrm{~cm}^{-1}(\mathrm{O}-\mathrm{H}$ stretching). The size of the particles as determined in a TEM study was $58.0 \pm 4.3 \mathrm{~nm}$, with the expected lognormal size distribution (Figure 1A and S1 in the Supporting Information). The size of the dried particles from the TEM study was in agreement with the size determined in small-angle neutron scattering (SANS) experiments using a colloidal dispersion of the nanoparticles in $\mathrm{D}_{2} \mathrm{O}$ (Figure 1B). Modelling the neutron scattering data (using a monodisperse core-shell model) yielded particle size of $60.2 \mathrm{~nm}$ (PDI 0.07); the slightly higher diameter determined in the SANS experiments could be explained by surface solvation of the nanoparticles in $\mathrm{D}_{2} \mathrm{O}$, which effectively increased their measured size. 

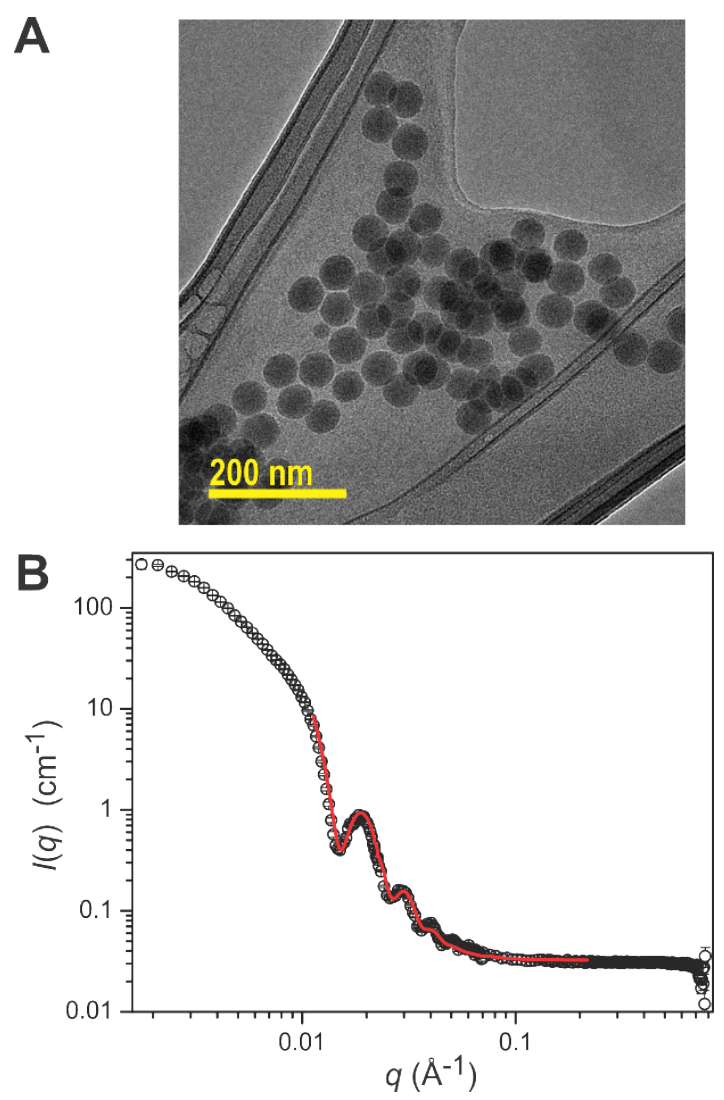

Figure 1. (A) TEM image of prepared $\mathrm{SiO}_{2}$ nanoparticles. (B) $\mathrm{SANS}$ data for the $\mathrm{SiO}_{2}$ nanoparticles in $\mathrm{D}_{2} \mathrm{O}$ colloidal solution (black circles) and best fit to the data (red solid line).

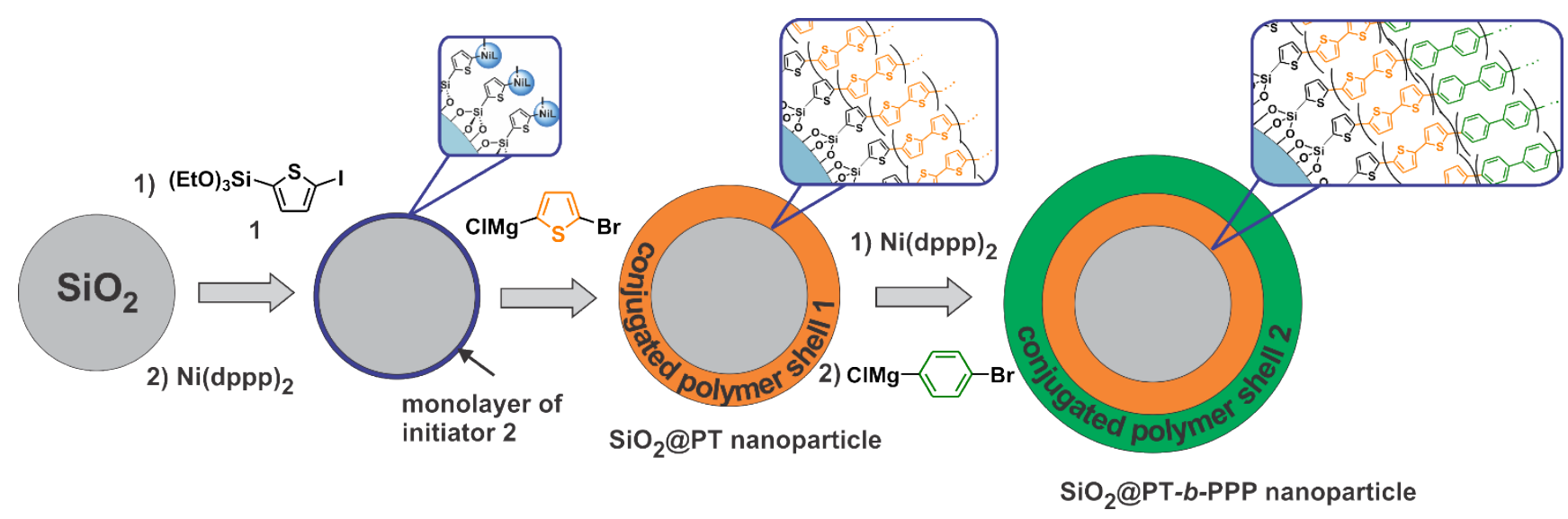

Figure 2. Preparation of a monolayer of $\mathrm{Ni}(\mathrm{II}) \mathrm{KCTP}$ catalytic initiator $\mathbf{2}$ immobilized on $\mathrm{SiO}_{2}$ nanoparticle surface, and subsequent surface-initiated polymerization to yield hybrid $\mathrm{SiO}_{2} @ \mathrm{PT}$ and $\mathrm{SiO}_{2} @$ PT- $b$-PPP nanoparticles. The polymer chain alignment normal to the nanoparticle surface is shown only for illustrative purpose and does not describe the actual complex morphology of the CP shell. 
Conjugated polymer (CP) grafted silica nanoparticles were prepared using the surface-initiated polymerization approach that we recently developed for the preparation of surface-confined CP thin films. ${ }^{56}$ It started with the covalent immobilization of 5-(triethoxysilyl)-2-iodothiophene precursor 1 on the silica nanoparticle surface followed by the reaction of the surface-functionalized nanoparticles with $\mathrm{Ni}(0)$ complex $\mathrm{Ni}(\mathrm{dppp})_{2}$ to yield surface-immobilized Ni(II) Kumada catalyst-transfer polymerization (KCTP) initiator 2 (Figure 2). After the Ni(II) catalyst 2 formation, the resulting nanoparticles were thoroughly washed with toluene to remove excess reagents. The Ni(II)-functionalized nanoparticles were then added to a solution of (5-bromothiophen-2-yl)magnesium chloride for the surface-initiated KCTP to effectively yield a surface-immobilized polythiophene (PT) shell on silica nanoparticles $\left(\mathrm{SiO}_{2} @ \mathrm{PT}\right)$ (Figure 2). At the end of polymerization, a portion of the reaction mixture was quenched with methanol to effectively stop the polymerization, and the resulting $\mathrm{SiO}_{2} @ \mathrm{PT}$ nanoparticles were sequentially washed with a series of organic solvents to remove excess reagents and solution byproducts (the unquenched portion of the reaction solution was preserved to prepare block copolymer functionalized nanoparticles, vide infra). A similar procedure using 4-bromophenylmagnesium chloride monomer effectively yielded nanoparticles with surface-immobilized poly( $p$-phenylene) (PPP) shell ( $\mathrm{SiO}_{2} @$ PPP nanoparticles). Although silica core and seemingly dense CP shells could not be unambiguously distinguished from each other in the TEM images, the increase in the size of the polymer-functionalized nanoparticles (compared to the initial $\mathrm{SiO}_{2}$ nanoparticles) was clearly observed (Figures 3A and B). Thus, the diameter of $\mathrm{SiO}_{2} @ \mathrm{PT}$ nanoparticles was estimated at $64 \pm 6$ nm (Figure $\mathrm{S} 2 \mathrm{~A}$ in the Supporting Information); this gave the thickness of surface-immobilized PT shell at $3 \mathrm{~nm}$ (based on the initial $\mathrm{SiO}_{2}$ nanoparticles size of $58 \mathrm{~nm}$ ). Similarly, the size of $\mathrm{SiO}_{2} @$ PPP nanoparticles was estimated at $68 \pm 6 \mathrm{~nm}$ (Figure S2B in the Supporting Information), which gave the thickness of PPP shell of $5 \mathrm{~nm}$. 

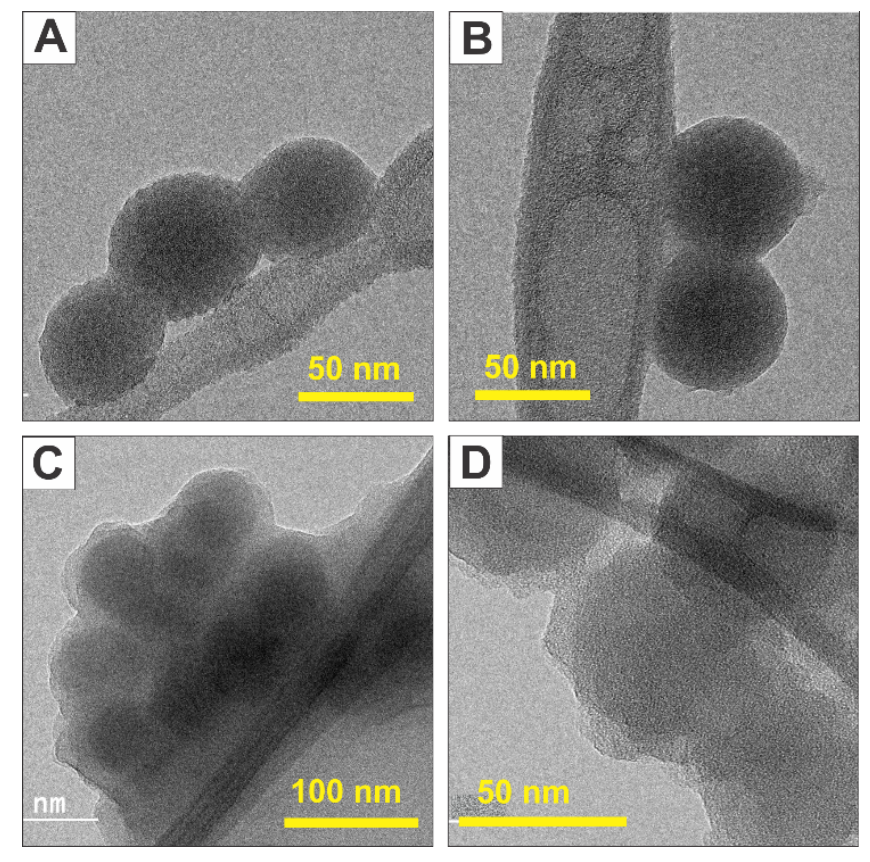

Figure 3. TEM images of $\mathrm{SiO}_{2} @ \mathrm{PT}(\mathrm{A}), \mathrm{SiO}_{2} @ \mathrm{PPP}(\mathrm{B}), \mathrm{SiO}_{2} @ \mathrm{PT}-b$-PPP (C), and $\mathrm{SiO}_{2} @$ PPP- $b$-PT (D) nanoparticles.

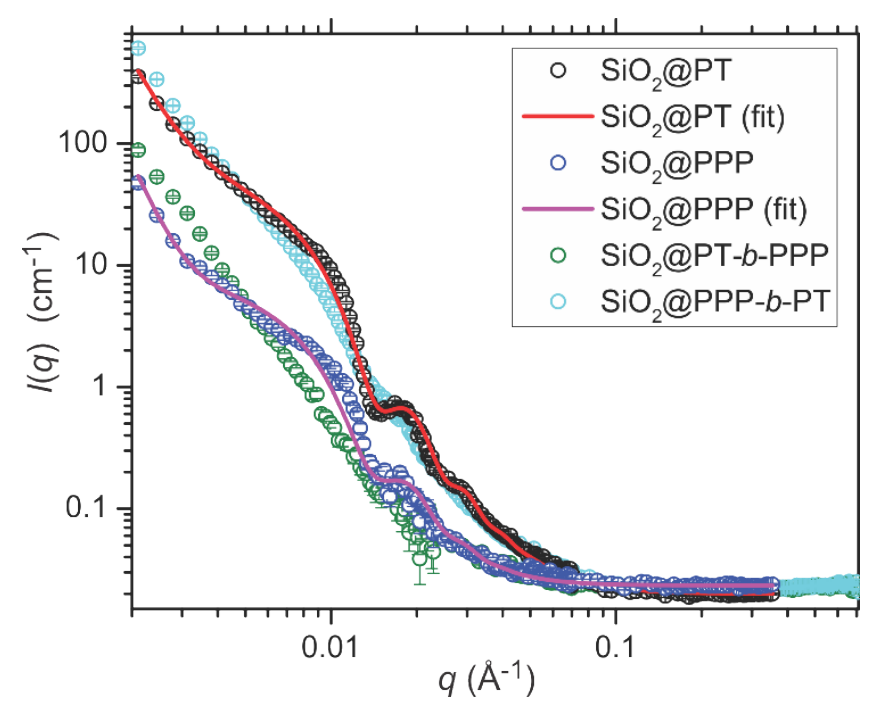

Figure 4. SANS data on hybrid nanoparticles in deuterated DCB (conc. $10 \mathrm{mg} / \mathrm{ml}$ ): $\mathrm{SiO}_{2} @ \mathrm{PT}$ (black circles, red trace - best fit), $\mathrm{SiO}_{2} @ \mathrm{PPP}$ (blue circles, magenta trace - best fit), $\mathrm{SiO}_{2} @ \mathrm{PT}-b$-PPP (green circles), and $\mathrm{SiO}_{2} @ \mathrm{PPP}-b$-PT (cyan circles). Experimental data fitting was performed using the model described in the text.

The electron microscopy images obtained on dried nanoparticles showed significant interparticle aggregation (Figures S3A and B in the Supporting Information). Significant aggregation is 
typical for electron microscopy images of dried core - CP shell nanoparticles, even those functionalized with a soluble polymer (e.g. P3HT), ${ }^{54}$ but it does not reflect the aggregation (or lack of it) in solutions of the same nanoparticles. Therefore we carried out extensive SANS studies on colloidal dispersions of the nanoparticles in deuterated 1,2-dichlorobenzene (DCB) to characterize structure and morphology of the nanoparticles directly in the colloidal solution. DCB was found to be a good solvent for the hybrid nanoparticles, yielding stable colloidal dispersions of both $\mathrm{SiO}_{2} @ \mathrm{PT}$ and $\mathrm{SiO}_{2} @ \mathrm{PPP}$ nanoparticles. SANS is a noninvasive technique which can deliver useful information about the shape, morphology and structure of individual colloidal particles in solution, but also allows to evaluate the extent of interactions between the particles. ${ }^{61,62}$ Conjugated polymers, especially those without long-chain alkyl solubilizing groups, have very limited solubility, and therefore polymer-functionalized particles were expected to show significant inter-particle aggregation. Surprisingly, we found that for both $\mathrm{SiO}_{2} @ \mathrm{PT}$ and $\mathrm{SiO}_{2} @$ PPP nanoparticles, aggregation features were not prevalent in the SANS plots, and we did observe characteristic oscillations indicating relatively low polydispersity of hybrid nanoparticles which existed in DCB as predominantly isolated nanoparticles with little inter-particle aggregation (Figure 4). The experimental SANS datasets were modeled using a core-shell model plus a power function to take into account the effect of inter-particle aggregation. This model produced a relatively good fit to the experimental data, and allowed estimating the polymer shell thickness of $2 \mathrm{~nm}$ for PT nanoparticles and $3 \mathrm{~nm}$ for PPP nanoparticles, with both values being in a reasonable agreement with the values obtained from the TEM studies. The sharp boundary between the polymer shell and the solvent and the relatively low overall thickness of the polymer shells indicated that the polymer chains were not extended into the solvent (as was previously observed in the case of "hairy" silica nanoparticles surface-grafted with soluble P3HT polymer ${ }^{49}$ ) but were instead strongly tilted parallel to the nanoparticle surface, forming a dense lamellar packing, where strong interchain interactions along with the low solubility of PT and PPP chains, precluded their expansion into the solvent. Despite good stability of $\mathrm{SiO}_{2} @ \mathrm{PT}$ and $\mathrm{SiO}_{2} @$ PPP colloidal suspensions in DCB, some inter-particle aggregation was still noticeable, 
appearing as a highly sloped Porod region at the low $q$-range (although the appearance of the low- $q$ Porod region could also be due to the high concentration, $10 \mathrm{mg} / \mathrm{ml}$, of the nanoparticles in solutions used for the SANS experiments).

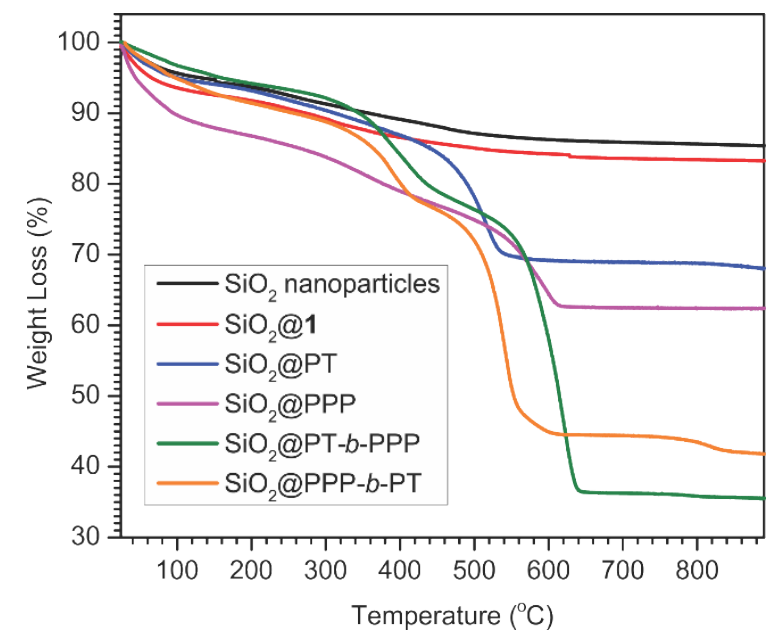

Figure 5. TGA studies (in air) of hybrid $\mathrm{SiO}_{2} @ \mathrm{CP}$ nanoparticles and precursors.

In order to quantify the amount of the grafted conjugated polymer shell, we carried out thermogravimetric analysis (TGA) studies in air. Heating the particles in air up to high temperature $\left(1000{ }^{\circ} \mathrm{C}\right)$ was expected to result in complete loss of the organic material, leaving behind only the inorganic silica core. For the baseline reference, we also obtained TGA curves for the bare silica nanoparticles, as well as the particles surface-functionalized with iodo precursor 1 (Figure 5). Despite prolonged drying of the particles in vacuo before acquiring TGA data, the bare $\mathrm{SiO}_{2}$ nanoparticles showed approximately a $14 \%$ weight drop at the temperature below $500{ }^{\circ} \mathrm{C}$. We attributed this drop to the loss of incorporated surfactant used in stabilization of microemulsion in the Stöber process, as well as the loss of adsorbed water. Thoroughly vacuum-dried nanoparticles surface-functionalized with iodo precursor 1 showed a total $17 \%$ drop of weight. Assuming that the relative difference with bare $\mathrm{SiO}_{2}$ nanoparticles was due to the loss of covalently immobilized iodo precursor $\mathbf{1}$, we could estimate the amount of 1 at $3 \%$ of the total weight of the nanoparticles. This allowed estimating surface grafting 
density of 1 at 1.5 molecules $\mathrm{nm}^{-2}$; this surface density was consistent with the value previously reported by Locklin for silyl-functionalized aromatic precursors on planar ITO surfaces. ${ }^{51}$

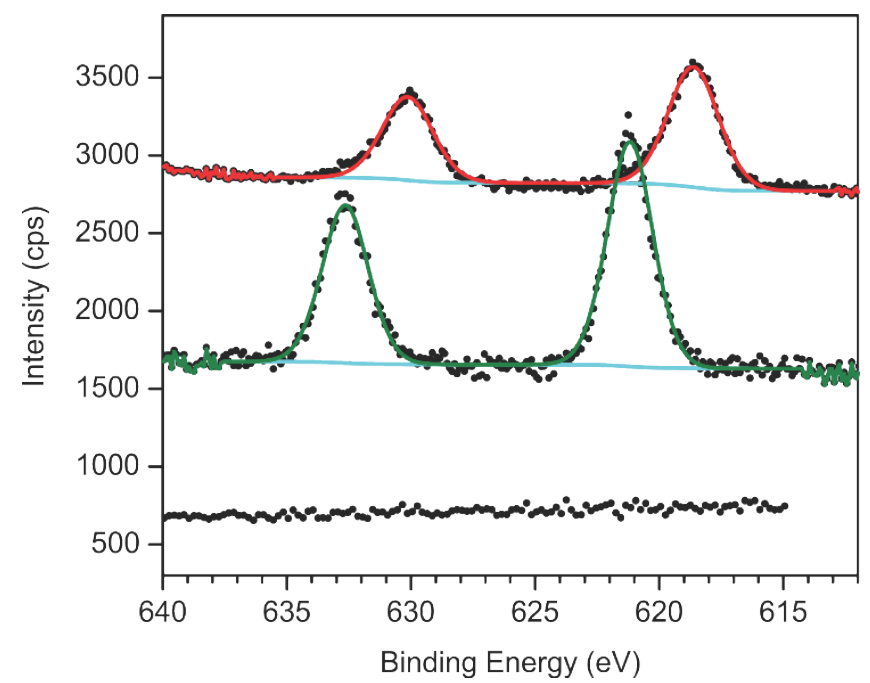

Figure 6. High-resolution I $3 d$ XPS spectra of silica nanoparticles (bottom trace), silica nanoparticles surface-functionalized with iodo precursor 1 before reaction with $\mathrm{Ni}(\mathrm{dppp})_{2}$ (middle green trace), and after reaction with $\mathrm{Ni}(\mathrm{dppp})_{2}$ upon conversion of $\mathbf{1}$ to $\mathrm{Ni}(\mathrm{II})$ external initiator $\mathbf{2}$ (top red trace). Shirley background (cyan traces) was applied to the top and middle spectra. Fitting parameters and deconvolution details are listed in Table S1 in the Supporting Information.

Reaction of the surface-functionalized nanoparticles with $\mathrm{Ni}(\mathrm{dppp})_{2}$ resulted in near quantitative conversion of iodo precursor 1 to the Ni(II) external initiator 2. The conversion was determined using high-resolution X-ray photoelectron spectroscopy (XPS), based on analysis of the iodine $3 d$ signal which is characterized by two well-resolved peaks in the XPS spectrum. ${ }^{56}$ The nanoparticles surfacefunctionalized with iodo precursor 1 displayed two signals at approximately 622 and $633 \mathrm{eV}$ which corresponded to I $3 d_{5 / 2}$ and I $3 d_{3 / 2}$ peaks (Figure 6, middle trace). Upon reaction of the nanoparticles with $\mathrm{Ni}(\mathrm{dppp})_{2}$, these signals shifted to lower binding energy at approximately 618 and $630 \mathrm{eV}$ corresponding to the iodide in the surface-immobilized $\mathrm{Ni}$ (II) initiator $\mathbf{2}$, with no observable signals from unreacted 1 (Figure 6, top trace). Assuming the controlled chain-growth polymerization mechanism, and considering quantitative conversion of surface-immobilized $\mathbf{1}$ to $\mathbf{2}$, we could estimate, based on the TGA weight loss, an average molecular weight of conjugated polymer in the shell for 
$\mathrm{SiO}_{2} @ \mathrm{PT}$ and $\mathrm{SiO}_{2} @ \mathrm{PPP}$ hybrid particles. Thus, for $\mathrm{SiO}_{2} @ \mathrm{PT}$ nanoparticles, the total weight loss was $31 \%$, and therefore the fraction of PT shell (the weight loss within the temperature interval $450-650$ ${ }^{\circ} \mathrm{C}$ ) was $17 \%$. Conversion of this percentage into number-average molecular weight $M_{\mathrm{n}}$ yielded a value of $1580 \mathrm{Da}$, which corresponded to an average degree of polymerization of 19 (see the Supporting Information for more details on the estimation). An estimate of the total length of a straightened PT chain with 19 thienyl repeating units was $8 \mathrm{~nm}$ (based on an AM1 semi-empirical computation). Considering the PT shell thickness of $2 \mathrm{~nm}$ (from SANS data), this indicated that PT polymer chains were oriented nearly parallel to the $\mathrm{SiO}_{2}$ core surface (tilting angle $\sim 14^{\circ}$ with respect to the nanoparticle surface), forming a lamellar densely packed shell. ${ }^{63}$

A similar analysis of $\mathrm{SiO}_{2} @$ PPP nanoparticles (TGA weight loss corresponding to PPP polymer $24 \%$ ) estimated a number-average molecular weight of polymer chains $M_{\mathrm{n}}$ of $2430 \mathrm{Da}$, which resulted in approximately 32 p-phenylene repeating units per chain. Based on the calculated (using a semiempirical AM1 method) p-phenylene repeating unit length of $0.43 \mathrm{~nm}$, the average length of a completely extended PPP chain was estimated at $14 \mathrm{~nm}$. Similar to the case of $\mathrm{SiO}_{2} @ \mathrm{PT}$ nanoparticles, this indicated that PPP chains were oriented nearly parallel to the $\mathrm{SiO}_{2}$ core surface (tilting angle $\sim 12^{\circ}$ with respect to the nanoparticle surface). The polymer coverage was uniform and complete, with a sharp boundary between the CP shells and environment as both SANS data and TEM images indicated. The low solubility of CP chains, and strong intermolecular interactions between unsubsituted CP chains were primarily responsible for these morphological and structural features, strongly contrasting with the structure and morphology of previously described "hairy" $\mathrm{SiO}_{2} @ \mathrm{P} 3 \mathrm{HT}$ nanoparticles. ${ }^{49}$ The CP chain alignment parallel to the nanoparticle surface and forming an oriented lamellar phase was consistent with our previous structural studies on PT thin films prepared by surface-initiated polymerization, ${ }^{56}$ as well as with previous reports on the molecular packing of a soluble P3HT polymer grafted to the surface of $\mathrm{ZnO}$ nanowires. ${ }^{30,} 64$ Such molecular organization and alignment in the $\mathrm{CP}$ shell had clear implications on the nanoparticles' photophysical properties as discussed later in the paper. 
In order to prepare nanoparticles surface-functionalized with block copolymer shell $\left(\mathrm{SiO}_{2} @ \mathrm{PT}\right.$ $b$-PPP), we used an unquenched portion of the reaction solution from the preparation of $\mathrm{SiO}_{2} @ \mathrm{PT}$ nanoparticles. Our previous studies on preparation of surface-confined PT thin films by surface-initiated polymerization demonstrated that a better quality film could be obtained by using intermediate regeneration of $\mathrm{Ni}$ (II) catalytic centers (as there was some premature degradation of the $\mathrm{Ni}$ (II) active catalytic centers during polymerization reaction). ${ }^{56}$ Therefore, after washing with toluene, the unquenched portion of $\mathrm{SiO}_{2} @ \mathrm{PT}$ nanoparticles was stirred with a fresh solution of $\mathrm{Ni}(\mathrm{dppp})_{2}$ for $48 \mathrm{~h}$. Then the nanoparticles were separated by centrifugation, washed with toluene, and added to a solution of 4-bromophenylmagnesium chloride monomer in THF (Figure 2). Upon completion of the surfaceinitiated polymerization, the reaction mixture was quenched with methanol, and $\mathrm{SiO}_{2} @ \mathrm{PT}-b-\mathrm{PPP}$ nanoparticles were sequentially washed with a series of organic solvents. The same approach was used to prepare $\mathrm{SiO}_{2} @$ PPP-b-PT nanoparticles, starting with an unquenched portion of the reaction solution from the preparation of $\mathrm{SiO}_{2} @ \mathrm{PPP}$ nanoparticles.

TGA analysis revealed substantial increase of polymer fraction in the block copolymer nanoparticles. For $\mathrm{SiO}_{2} @ \mathrm{PT}-b$-PPP nanoparticles, weight increase was 33\% relative to $\mathrm{SiO}_{2} @ \mathrm{PT}$ nanoparticles, and for $\mathrm{SiO}_{2} @$ PPP- $b$-PT nanoparticles the corresponding weight increase was $18 \%$ relative to the parent $\mathrm{SiO}_{2} @$ PPP nanoparticles (Figure 5). In both cases, this indicated successful incorporation of the second polymer block using the controlled KCTP process. The higher weight increase in the case of $\mathrm{SiO}_{2} @ \mathrm{PT}-b$-PPP nanoparticles reflected the higher reactivity of the surfaceinitiated polymerization originating from the PT layer and leading to the PPP outer layer formation. Electron microscopy images of the dried nanoparticles showed significant aggregation of the block copolymer functionalized nanoparticles, with nanoparticle clusters dominating microscopy images even after extended ultrasonication in the good solvent DCB (Figures 3C and D, and Figures S3C and D in the Supporting Information). Although electronic microscopy images were acquired on dry samples, the significant aggregation in solution was also evident from SANS data analysis, where a high-slope 
Porod plot was a dominating feature at the low- $q$ region (corresponding to the large-size aggregates), and no characteristic oscillations were noticeable at higher $q$ values (Figure 4). Due to the aggregation features dominating SANS plots, we were not able to successfully model the experimental data in order to determine shell thickness of the block copolymer shells, or sharpness of the interface between the block copolymer shell and solvent. The high-resolution electronic microscopy images showed relatively uniform coverage in the case of $\mathrm{SiO}_{2} @$ PT- $b$-PPP nanoparticles, but rough and non-uniform CP shell surface with shell interpenetration between the particles in the case of $\mathrm{SiO}_{2} @$ PPP-b-PT nanoparticles. The clearly observed morphological differences between the two kinds of block copolymer functionalized nanoparticles could reflect differences in the molecular organization and the packing in the polymer shells, and were responsible for the spectroscopic and photophysical properties of the hybrid systems which are discussed below.

Spectroscopic properties of the nanoparticles. Structurally defined fluorescent conjugated block copolymer shells on the nanoparticle surface allow for the study of photoexcitation energy transfer in the nanoscale condensed systems, with the goal to tune spectroscopic/photophysical characteristics of such systems for potential practical applications. A detailed understanding of energy transfer in condensed $\pi$-electron conjugated polymer systems remains complicated due to the problems associated with deciphering the relative contribution of intermolecular and intramolecular pathways. The interplay between these two pathways has received substantial attention in the literature. ${ }^{65-67}$ The intermolecular energy transfer occurs by a through-space dipole - induced dipole mechanism (similar to the FRET mechanism for energy transfer between small-molecule chromophores) and is enhanced by the multitude of close interchain contacts in the condensed phase. Similarly, the intramolecular energy transfer can happen by the through-space mechanism, but in the presence of strong $\pi$-electronic coupling along $\mathrm{CP}$ chain there is also the possibility of facile long-range energy transfer due to wavefunction delocalization, which is generally referred to as the through-bond (Dexter) energy transfer (also known as an exchange mechanism). ${ }^{68-70}$ The through-bond mechanism may become particularly efficient in 
the conditions that maximize electronic conjugation along the polymer backbone, e.g. in the case of extended and highly ordered conjugated polymer chains. ${ }^{71}$ With PT- $b$-PPP conjugated block copolymer shells, we expected an efficient energy transfer via the through-space dipole - induced dipole mechanism from the higher-energy PPP to the lower-energy PT chromophores as there is a strong overlap between PPP emission and PT absorption. In addition, the unique morphology and molecular organization of the surface-immobilized polymer blocks could allow for additional inter-chromophore interactions resulting in a more complex spectroscopic behavior.

Spectroscopic properties of the polymer-grafted hybrid nanoparticles were studied in their colloidal solutions in 1,2-dichlorobenzene (DCB). Although unsubstituted PT and PPP polymers are not soluble in organic solvents, using DCB resulted in indefinitely stable colloidal suspensions of the polymer-grafted nanoparticles, likely due to the good solvation of conjugated polymer shell via aromatic interactions with the solvent. UV/vis absorption spectra of $\mathrm{SiO}_{2} @ \mathrm{PT}$ and $\mathrm{SiO}_{2} @ \mathrm{PPP}$ nanoparticles displayed broad vibronically structured bands at 370-620 nm and 300-420 nm, which could be attributed to the absorption by PT and PPP shells, respectively (Figure 7A). The broad absorption spectrum of $\mathrm{SiO}_{2} @ \mathrm{PT}$ nanoparticles with pronounced vibronic structure was similar to the absorption spectra of PT thin films prepared using surface-initiated polymerization approach, ${ }^{56}$ and was indicative of an ordered molecular organization of rigidified polymer molecules, and of a certain level of uniformity in the polymer chains alignment. ${ }^{72-74}$ The similarly observed vibronic structure in $\mathrm{SiO}_{2} @ \mathrm{PPP}$ absorption spectra was also consistent with the spectra of PPP thin films prepared by surface-initiated polymerization. ${ }^{53}$ Therefore, this observation suggested a certain level of molecular organization in the PPP shell. The ratio of the intensities of $0-0$ to 0 - 1 vibronic bands was found to be less than 1 ( $\sim 0.8$ for $\mathrm{SiO}_{2} @ \mathrm{PPP}$ and 0.7 for $\left.\mathrm{SiO}_{2} @ \mathrm{PT}\right)$ which pointed to the predominant interchain electronic coupling in the organic shell typical of the formation of weakly coupled polymer H-aggregates. ${ }^{75-77}$ Formation of the interchain $\mathrm{H}$-aggregates was consistent with the conclusion that the polymer chains in the shell were densely packed in a nearly coplanar fashion relative to the nanoparticle surface (vide supra). This 

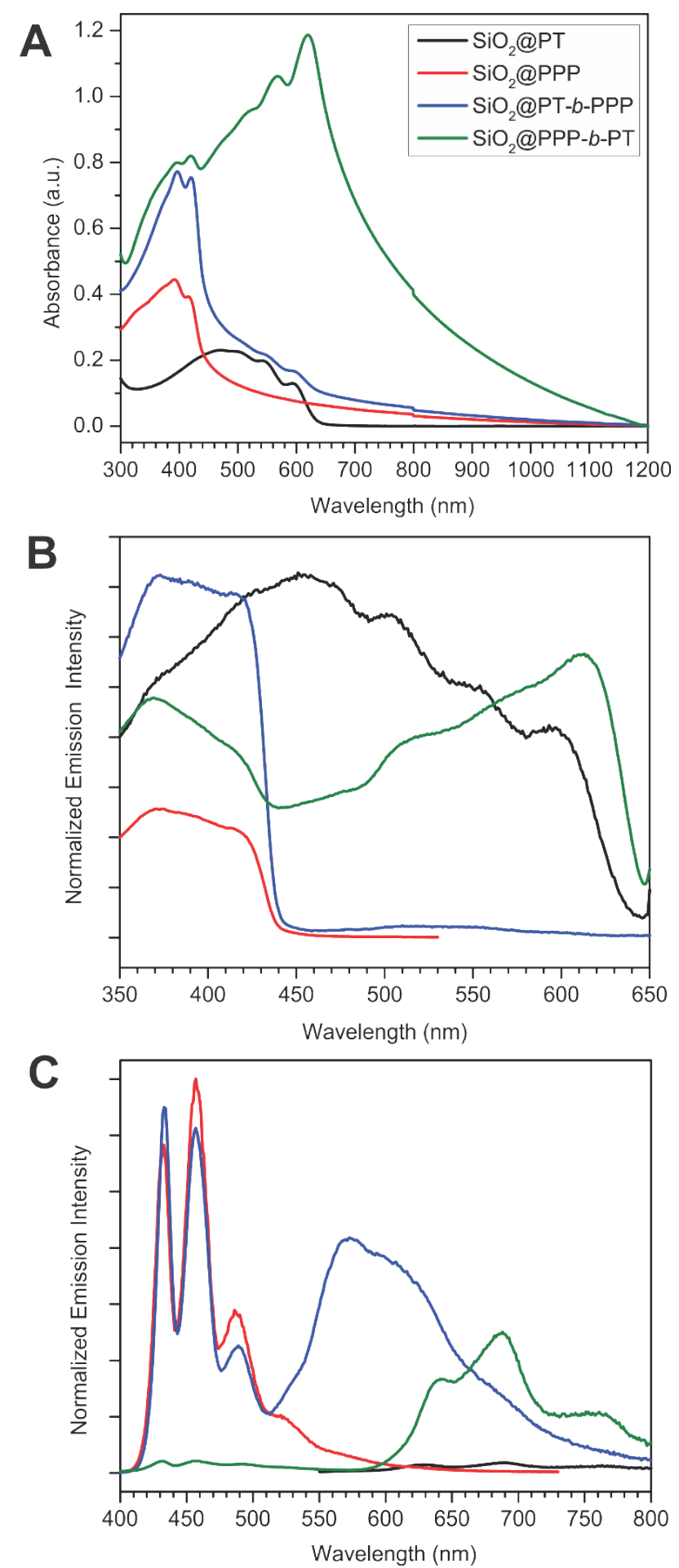

Figure 7. Steady-state spectroscopic data on hybrid nanoparticles in colloidal solutions in DCB (conc. $0.5 \mathrm{mg} / \mathrm{ml}$ ): UV/vis absorption (A), fluorescent excitation (B), and fluorescent emission (C). The excitation and emission spectra were normalized by corresponding extinction coefficients and quantum yields. Emission quantum yields: $\mathrm{SiO}_{2} @ \mathrm{PT}<0.001 ; \mathrm{SiO}_{2} @ \mathrm{PPP} 0.26 ; \mathrm{SiO}_{2} @ \mathrm{PT}-b-\mathrm{PPP} 0.02$; $\mathrm{SiO}_{2} @$ PPP-b-PT 0.01. 
molecular arrangement was similar to the previously studied bulk organization of the PT thin films, which was reflected in the similarity between the absorption spectra of the CP-functionalized nanoparticles and the corresponding plane thin films. Overall, the hybrid nanoparticles were remarkably stable and showed no change in absorption spectra even after prolonged ultrasonication in various solvents.

$\mathrm{SiO}_{2} @$ PPP nanoparticles showed intense fluorescence with a vibronically structured fluorescent emission band at 400-550 nm, whereas $\mathrm{SiO}_{2} @ \mathrm{PT}$ nanoparticles were practically non-emissive, displaying a weak vibronically structured emission band at 600-800 nm (Figure 7C). Fluorescent excitation spectra were generally consistent with the absorption spectra thus indicating that the emission bands originated from electronic excitation of the weakly coupled polymer chromophores within the polymer shells (Figure 7B).

Although one could expect similarity between the spectroscopic characteristics of the two kinds of block copolymer functionalized nanoparticles $\left(\mathrm{SiO}_{2} @ \mathrm{PT}-b-\mathrm{PPP}\right.$ and $\left.\mathrm{SiO}_{2} @ \mathrm{PPP}-b-\mathrm{PT}\right)$, we found them to be strikingly different. Incorporating an outer PT sublayer in $\mathrm{SiO}_{2} @ \mathrm{PPP}$ nanoparticles was accompanied by the appearance of an intense vibronically structured PT band in addition to the initial PPP band (Figure 7A). In striking contrast to $\mathrm{SiO}_{2} @ \mathrm{PT}$ nanoparticles, the PT absorption band in $\mathrm{SiO}_{2} @$ PPP-b-PT nanoparticles was substantially bathochromically shifted, with the ratio of intensities of $0-0$ to $0-1$ vibronic bands being greater than $1(\sim 1.2)$. These two observations, along with the increasing extinction coefficient, indicated predominance of the intramolecular $\mathrm{J}$-aggregates. ${ }^{76,} 77$ Within the weak coupling framework model developed by Spano, polymer J-aggregates result from the intramolecular electronic coupling along the stretched planarized PT chains, and with only a small contribution from the interchain coupling. ${ }^{78,79}$ Formation of the polymer J-aggregates was also consistent with an increased intensity of the vibronically structured PT band in the emission spectrum, obtained upon excitation of the PPP chromophore at $380 \mathrm{~nm}$ (Figure 7C). Indeed, the near absence of the PPP emission band indicated a highly efficient intra-shell photoexcitation energy transfer from the 
higher-energy PPP to the lower-energy PT chromophores. An excitation spectrum acquired upon monitoring the PT emission band (Figure 7B) showed the presence of both PPP and PT bands (with the latter showing pronounced J-aggregate character), and indicated the possibility of PT fluorescence originating both through direct excitation of the PT chromophore and via an efficient intra-shell "outward" energy transfer from the photoexcited PPP chromophore.

Very surprisingly, reversing the order of the chromophores in the block copolymer shell in $\mathrm{SiO}_{2} @ \mathrm{PT}-b$-PPP nanoparticles resulted in some major changes in the optical spectra. The UV/vis absorption spectrum showed bands corresponding to both PT and PPP chromophores, and indicated the predominance of intermolecularly weakly coupled H-aggregates in both polymer blocks (as the ratio of 0-0 to 0-1 vibronic intensities was less than 1 for both PT and PPP chromophores). The emission spectrum obtained upon excitation of the PPP chromophore at $380 \mathrm{~nm}$ displayed a strong PPP fluorescence band (indicative of the lower efficiency of energy transfer from the photoexcited PPP chromophore), but also a new intense broad band with a maximum at $570 \mathrm{~nm}$ (Figure 7C). The wavelength range corresponding to this new band was too short for it to be assigned to a PT emission. The fluorescence excitation spectrum of the nanoparticles (Figure 7B) revealed an intense band corresponding to the PPP chromophore and a very weak band due to the PT chromophore. This indicated that the broad $570 \mathrm{~nm}$ emission band could be generated only via the excitation of the higherenergy PPP chromophore but not via the excitation of the lower-energy PT chromophore. Based on these observations, we attributed the new $570 \mathrm{~nm}$ emission band in the $\mathrm{SiO}_{2} @ \mathrm{PT}-b$-PPP nanoparticles to the formation of a PPP/PT exciplex. Emissive exciplexes are excited state species which are observed in thin-film spectra of conjugated polymers where they are formed via electronic interaction of an excited-state chromophore in one polymer chain with a ground-state chromophore on a closely positioned neighboring chain. ${ }^{80}$ Previously, formation of emissive exciplexes was observed at the interlayer interface between two different conjugated polymers in bilayer thin films. ${ }^{81,82}$ The lack of a new absorption band in the UV/vis spectrum or any new feature in the excitation spectrum indicated 
that the species responsible for the $570 \mathrm{~nm}$ emission could not be directly accessed from the ground state and thus corresponded to the interpolymer exciplex formation. The relatively high intensity of the PPP emission band also indicated a less efficient energy transfer to the lower-energy PT chromophore. Thus, unlike the highly efficient "outward" energy transfer from the inner PPP to the outer PT chromophore in the case of $\mathrm{SiO}_{2} @$ PPP- $b$-PT nanoparticles, the "inward" energy transfer in $\mathrm{SiO}_{2} @ \mathrm{PT}-$ $b$-PPP nanoparticles was much less efficient and resulted in the appearance of both PPP and exciplex emission bands (Figure 7C).

The higher efficiency of the "outward" photoexcitation energy migration in $\mathrm{SiO}_{2} @ \mathrm{PPP}-b-\mathrm{PT}$ nanoparticles correlated well with the predominance of J-aggregates in the PT chromophore. Indeed, the enhanced intramolecular electronic coupling along the stretched and planarized polymer chains in J-aggregates would further facilitate the intramolecular energy transfer via increasing contribution of the through-bond (Dexter) mechanism. Similar enhancement via the through-bond mechanism contribution was previously observed in the stretched and uniformly aligned fluorescent conjugated polymer chains in nematic liquid crystalline media. ${ }^{71}$

In the case of $\mathrm{SiO}_{2} @ \mathrm{PT}-b$-PPP nanoparticles, predominance of the weakly coupled interchain H-aggregates could diminish the efficiency of "inward" energy transfer but also created proper structural conditions for the formation of an interpolymer exciplex. Such an exciplex could be formed at the thin well-defined interface between uniformly aligned PT and PPP chromophores, and could act as a blocking layer preventing efficient energy transfer from PPP to the PT chromophore. This indicated major differences in the structural organization and morphology of the block copolymer shells. In order to further understand the nanoparticles structure and correlation with their different spectroscopic properties, we carried out a detailed time-resolved spectroscopy investigation.

Transient absorption spectroscopy study of the nanoparticles. Time-resolved optical spectroscopy studies on hybrid conjugated polymer nanoparticles could provide valuable information 
on the excited-state dynamics of both radiative and non-radiative photophysical processes occurring in the polymer shell such as exciton formation and decay, energy transfer, etc.

The transient absorption spectroscopy on $\mathrm{SiO}_{2} @ \mathrm{PT}$ and $\mathrm{SiO}_{2} @ \mathrm{PPP}$ hybrid nanoparticles in colloidal suspension in DCB was investigated using a $380 \mathrm{~nm}$ excitation which was sufficient for exciting both PPP and PT chromophores. Representative transient absorption spectra of $\mathrm{SiO}_{2} @ \mathrm{PPP}$ nanoparticles are shown in Figure 8A. Two broad negative bands ranging between 430 and $560 \mathrm{~nm}$ and approximately coinciding with steady-state emission spectrum of $\mathrm{SiO}_{2} @ \mathrm{PPP}$ could be attributed to the combination of PPP chromophore and ground-state bleach (GSB) and stimulated emission (SE) bands, whereas a positive band near $400 \mathrm{~nm}$ was due to the PPP chromophore excited-state absorption. An intense positive band spanning the wavelength region above $560 \mathrm{~nm}$ could be attributed to absorption of the interchain polaron pair, and is consistent with the predominance of interchain $\mathrm{H}$-aggregates found in steady-state spectra. In order to separate different contributions in the combined transient absorption spectra, we carried out global analysis of the transient absorption time-profiles to obtain wavelengthdependent decay spectra. ${ }^{83-86}$ The wavelength-dependent decay spectra could be described by a sum of exponentials to recover the lifetimes and corresponding spectra of the relaxation dynamics, and are presented in Figure 9B. Two lifetimes of $\tau_{1}=8 \pm 3$ ps and $\tau_{2}=20 \pm 4$ ps were needed to accurately describe the ultrafast excited-state relaxation dynamics of the PPP chromophore in the $\mathrm{SiO}_{2} @ \mathrm{PPP}$ nanoparticles. The decay spectrum corresponding to the shorter lifetime $\tau_{1}$ was localized in the higher energy part of the spectral range, and showed a positive excited-state absorption band below $430 \mathrm{~nm}$ and a more narrow negative band with maximum at $460 \mathrm{~nm}$, as well as a positive band at $500 \mathrm{~nm}$. The component corresponding to the longer lifetime $\tau_{2}$ incorporated a broad negative band with a maximum at $520 \mathrm{~nm}$, and the broad positive singlet exciton band above $560 \mathrm{~nm}$. Both the SE and GSB bands were bathochromically shifted compared to the steady-state absorption and fluorescence spectra (Figure 7). Such bathochromic shifts have been previously noticed in transient absorption spectroscopy studies of conjugated polymers, and could be explained by effective isolation by the transient spectroscopy of the 
excited sub-population, as opposed to the entire ground-state ensemble probed by steady-state spectroscopy. ${ }^{87}$ Overall, the decay spectrum corresponding to $\tau_{1}$ could be assigned to the formation of initial singlet Frenkel excition, whereas the decay spectrum corresponding to $\tau_{2}$ could be related to the subsequent relaxation to interchain polaron pair. ${ }^{88}$ It should be noted that both processes were rather fast and happened within a picosecond time frame.
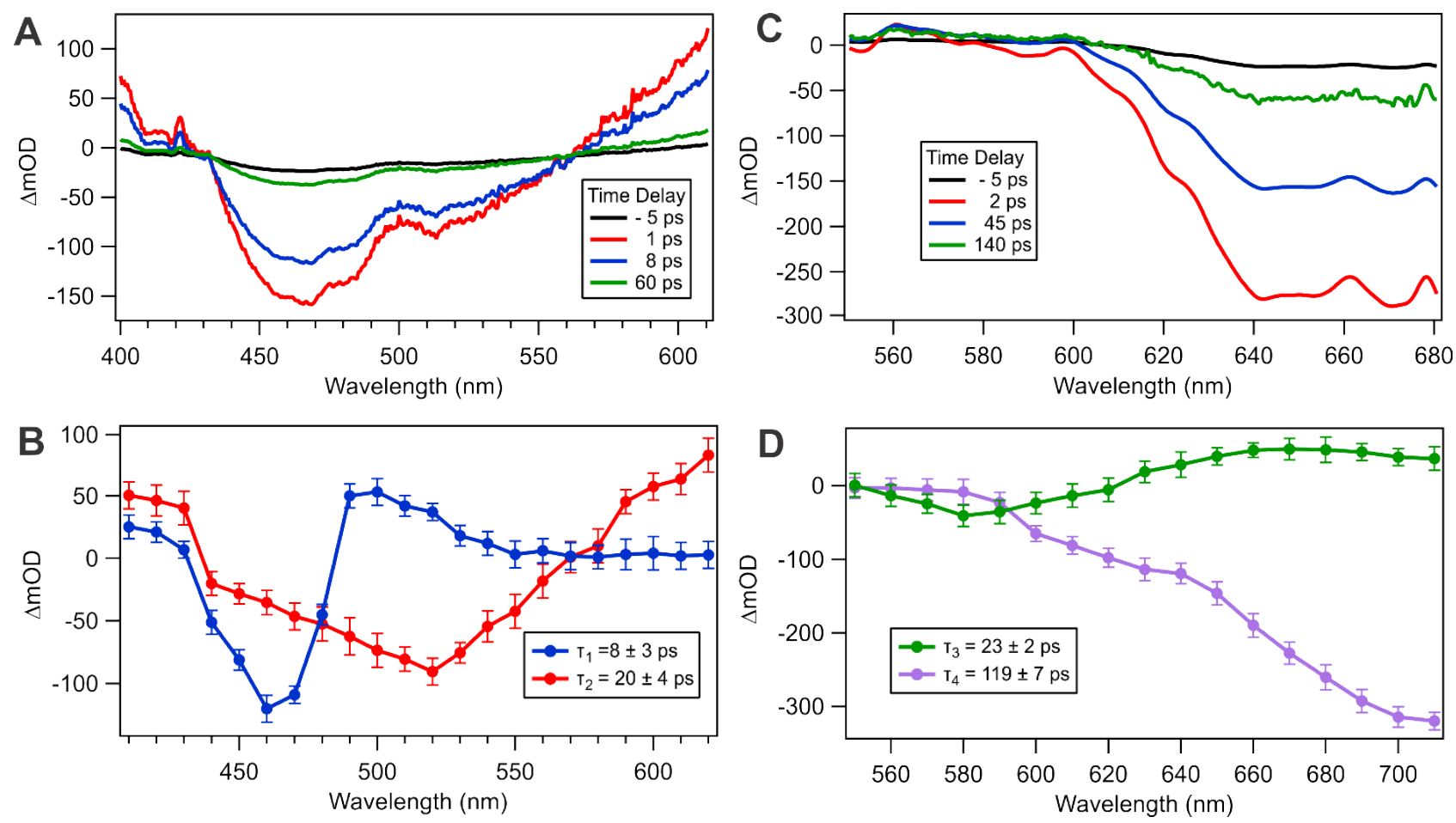

Figure 8. Representative transient absorption spectra of colloidal solution of $\mathrm{SiO}_{2} @ \mathrm{PPP}$ nanoparticles (A) and $\mathrm{SiO}_{2} @ \mathrm{PT}$ nanoparticles (C) in DCB (conc. $0.5 \mathrm{mg} / \mathrm{ml}$ ) obtained using $380 \mathrm{~nm}$ pump pulses. Decay spectra for $\mathrm{SiO}_{2} @ \mathrm{PPP}(\mathrm{B})$ and $\mathrm{SiO}_{2} @ \mathrm{PT}$ (D) nanoparticles obtained from global analysis of the time-dependent transient absorption spectra.

Figure 8C shows representative transient absorption spectra of $\mathrm{SiO}_{2} @$ PT hybrid nanoparticles. A broad negative band was observed at the spectral region above $580 \mathrm{~nm}$. This band was dominated by SE since it occurred in the spectral range of fluorescent emission but not absorption of the PT chromophore. Two lifetimes were needed to accurately describe the excited-state relaxation dynamics (Figure 8D). The decay spectrum corresponding to the shorter lifetime $\tau_{3}=23 \pm 2$ ps showed a small 
negative GSB band with maximum at $580 \mathrm{~nm}$, and a broad positive band with maximum at $675 \mathrm{~nm}$. The positive band could be mainly attributed to the absorption of the initially formed Frenkel exciton. The decay spectrum corresponding to the substantially longer lifetime $\tau_{4}=119 \pm 7$ ps was dominated by the broad negative SE band spanning above $580 \mathrm{~nm}$. The long lifetime associated with this band likely indicated that it was due to the long-lived interchain polaron state.

The transient absorption spectra of $\mathrm{SiO}_{2} @$ PPP-b-PT block copolymer functionalized hybrid nanoparticles were obtained upon excitation of the PPP chromophore using $380 \mathrm{~nm}$ pulses (Figure 9A). At first glance, it appeared like a combination of the time-resolved spectra of $\mathrm{SiO}_{2} @ \mathrm{PPP}$ and $\mathrm{SiO}_{2} @ \mathrm{PT}$ systems. The corresponding decay spectra from global analysis (Figure 9B) required five lifetimes of $\tau_{1}=3 \pm 1 \mathrm{ps}, \tau_{2}=19 \pm 2 \mathrm{ps}, \tau_{3}=27 \pm 3 \mathrm{ps}, \tau_{4}=128 \pm 5 \mathrm{ps}$, and $\tau_{5}=11 \pm 2 \mathrm{ps}$ to accurately describe the ultrafast excited-state relaxation dynamics, and the lifetimes $\tau_{1}-\tau_{4}$ nicely matched the corresponding lifetimes observed for the homopolymer systems $\mathrm{SiO}_{2} @ \mathrm{PPP}$ and $\mathrm{SiO}_{2} @ \mathrm{PT}$. The decay spectra associated with $\tau_{1}$ and $\tau_{2}$ could be assigned to PPP chromophore, and they were predominantly localized in the PPP transient absorption wavelength range, whereas the decay spectra associated with $\tau_{3}$ and $\tau_{4}$ were assigned to the PT chromophore, and they were localized in the longer-wavelength spectral range. Interestingly, the transient absorption spectra bands associated with PT chromophore were more narrow and significantly hypsochromically shifted relative to the similar bands in the transient absorption spectra of $\mathrm{SiO}_{2} @ \mathrm{PT}$ system (Figure 8C). This was consistent with the predominance of intrachain coupled J-aggregates in the PT chromophore of $\mathrm{SiO}_{2} @ \mathrm{PPP}-b-\mathrm{PT}$ system. It is striking that the relative amplitudes of the transient spectra associated with the PT chromophore (and the related decay spectra) were significantly higher than the amplitudes associated with the PPP chromophore absorption (Figures 9A and B). The dominance of the features associated with the PT chromophore in the transient absorption spectra was reflective of the efficient energy transfer towards this chromophore in the $\mathrm{SiO}_{2} @ \mathrm{PPP}-b$-PT nanoparticles, as was preliminarily deduced from the analysis of steady-state spectroscopy data (vide supra). Indeed, the fifth lifetime $\tau_{5}$ could describe the kinetics 
of the fast energy transfer from PPP to PT chromophores, as the corresponding decay spectrum showed both a positive band associated with the excited-state (Frenkel exciton) absorption of PPP chromophore, and an SE band of the PT chromophore (Figure 9B).
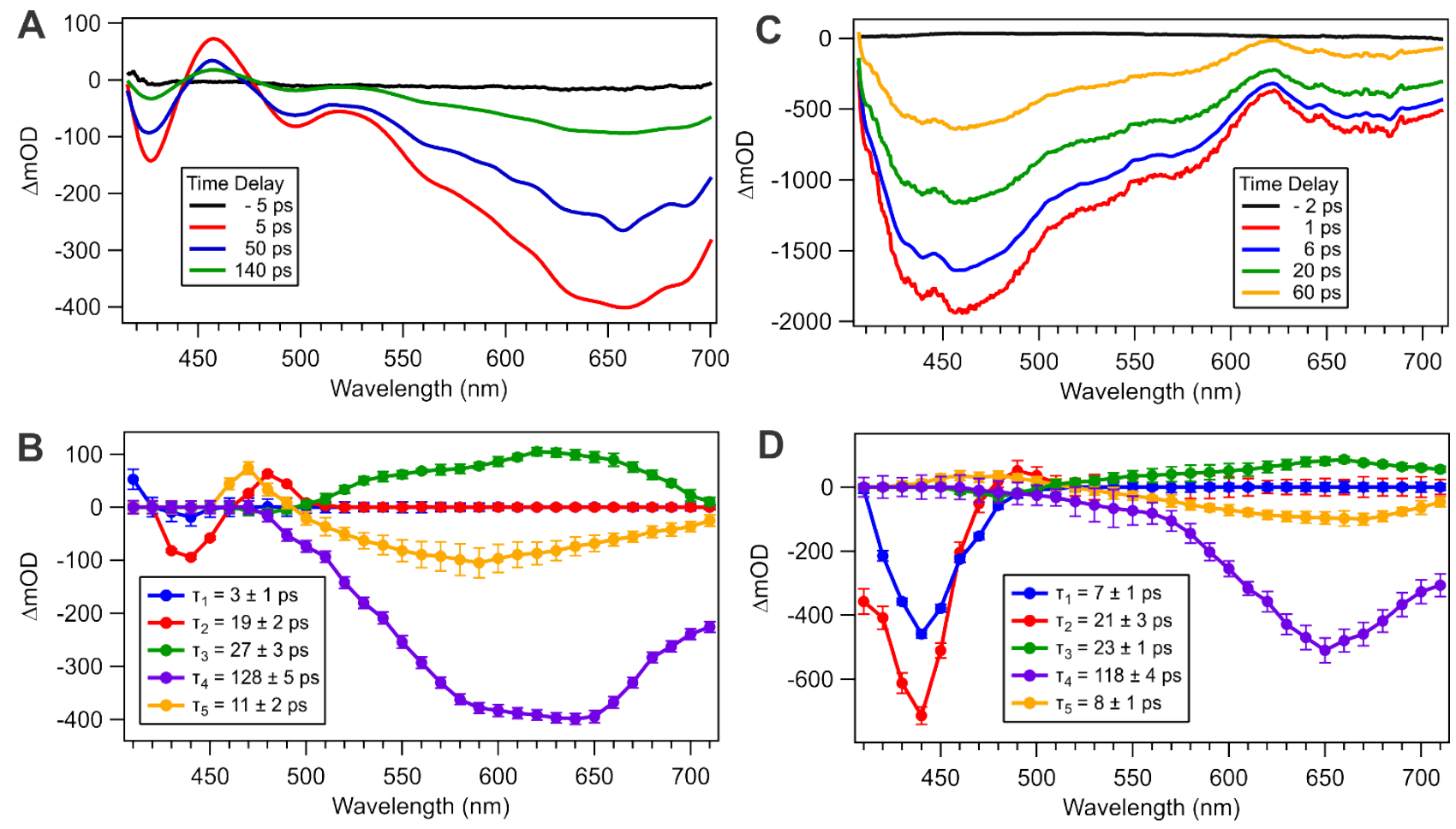

Figure 9. Representative transient absorption spectra of colloidal solution of $\mathrm{SiO}_{2} @ \mathrm{PPP}-b$-PT nanoparticles (A) and $\mathrm{SiO}_{2} @$ PPP-b-PT nanoparticles (C) in DCB (conc. $0.5 \mathrm{mg} / \mathrm{ml}$ ) obtained using 380 nm pump pulses. Decay spectra for $\mathrm{SiO}_{2} @$ PPP- $b$-PT (B) and $\mathrm{SiO}_{2} @$ PT- $b$-PPP (D) nanoparticles obtained from global analysis of the time-dependent transient absorption spectra.

The transient absorption spectra of $\mathrm{SiO}_{2} @ \mathrm{PT}-b$-PPP hybrid block copolymer nanoparticles were obtained using $380 \mathrm{~nm}$ excitation pulses (Figure 9C). Although features associated with both PPP and PT chromophores could be observed, the spectra were strikingly different from the spectra obtained for the $\mathrm{SiO}_{2} @$ PPP- $b$-PT system. Overall, transient absorption spectra of $\mathrm{SiO}_{2} @ \mathrm{PT}-b$-PPP nanoparticles were dominated by the PPP chromophore. A broad negative absorption centered near $460 \mathrm{~nm}$ could be attributed to a GSB band of the PPP chromophore, whereas a smaller-amplitude band at around $670 \mathrm{~nm}$ was associated with the PT chromophore. There was also an excited-state absorption band at $\sim 620 \mathrm{~nm}$. 
This band could be assigned to the absorption of PPP/PT exciplex which was earlier identified through its intense fluorescence band in the steady-state emission spectra of the $\mathrm{SiO}_{2} @ \mathrm{PT}-b$-PPP system. As shown in the decay spectra (Figure 9D), five lifetimes of $\tau_{1}=7 \pm 1 \mathrm{ps}, \tau_{2}=21 \pm 3 \mathrm{ps}, \tau_{3}=23 \pm 1 \mathrm{ps}, \tau_{4}$ $=118 \pm 4 \mathrm{ps}$, and $\tau_{5}=8 \pm 1 \mathrm{ps}$ were required to accurately describe the ultrafast excited-state relaxation dynamics of the nanoparticles. Similar to the case of $\mathrm{SiO}_{2} @ \mathrm{PPP}-b$-PT nanoparticles, $\tau_{1}$ and $\tau_{2}$ could be assigned to the PPP chromophore, and $\tau_{3}$ and $\tau_{4}$ were assigned to the PT chromophore. Once again, the lifetime $\tau_{5}$ corresponding to the decay spectrum showing both PPP excited-state (exciton) absorption and PT stimulated emission, was assigned to the kinetics of intra-particle energy transfer from PPP to PT chromophore. The amplitude associated with the lifetime $\tau_{5}$ was much smaller than in the case of $\mathrm{SiO}_{2} @$ PPP- $b$-PT nanoparticles, and reflected the lower efficiency of the "inward" energy transfer in $\mathrm{SiO}_{2} @$ PT- $b$-PPP system, in good agreement with the conclusion obtained from the steady-state spectroscopy analysis of this system (vide supra).

Structure of the hybrid nanoparticles. Structural and spectroscopic studies described in this work permitted some generalizations to be made regarding similarities and differences between the various $\mathrm{SiO}_{2} @ \mathrm{CP}$ hybrid nanoparticles prepared by surface-initiated Kumada catalyst-transfer polymerization. The specific spatial and reactivity constraints imposed on the polymer chains growing on the nanoparticle surface via controlled chain-growth polymerization process made these hybrid nanoparticles distinctly unique relative to other, previously described organic/inorganic core-shell nanoparticles. It appears reasonable that, as surface-initiated polymerization proceeded, the interplay between attractive van der Waals interactions between the surface-confined polymer chain and polymersolvent interactions as well as the tendency to form densely packed polymer layer forced the polymer chains to tilt over the nanoparticle surface and form lamellar phase of only a few nanometers thick dense polymer shell. Such packing resulting in close interchain contacts was reflected in the predominance of interchain H-aggregate features in optical spectra. The structure of the homopolymer shells appeared to be similar for both $\mathrm{SiO}_{2} @ \mathrm{PPP}$ and $\mathrm{SiO}_{2} @ \mathrm{PT}$ systems, and was similar to the structure and molecular 
packing in the corresponding homopolymer thin films. Thus, we could conclude that nanoscale confinement did not play any determining role for the $\mathrm{SiO}_{2} @ \mathrm{CP}$ systems. Differences started appearing upon introducing the second, outer, $\mathrm{CP}$ chromophore in the block copolymer nanoscale systems. The $\mathrm{SiO}_{2} @$ PPP- $b$-PT nanoparticles displayed efficient “outward" energy transfer from the "inner" PPP to the "outer" PT chromophores. The PT chromophore showed dominant spectroscopic features associated with the strongly coupled intrachain J-aggregate formation; the PT chromophore also dominated the time-resolved spectroscopy of this system. Such features indicated the unique spatial constraints imposed by the nanoscale particle environment. Apparently, higher molecular rigidity of the PPP conjugated backbone ${ }^{89,} 90$ resulted in the PT polymer chains grafted at the end of PPP chains being less tilted towards the nanoparticle surface and instead forming more planarized rigid PT chains exposed into the solvent (as in the case of "hairy" nanoparticles). Strong intramolecular electronic coupling in such extended PT chains promoted efficient energy transfer via the through-bond (Dexter-type) mechanism, similar to the previously described case of stretched and aligned CP chains. ${ }^{71}$

For the case of $\mathrm{SiO}_{2} @$ PT- $b$-PPP nanoparticle system the PPP chains in the "outer" sublayer were more tilted toward the nanoparticle surface, likely forming a densely packed lamellar phase, with a welldefined and tight interface with the underlying PT chromophore. Such a tight interface between PPP and PT chromophores could explain formation of the PPP/PT exciplex state at the narrow and welldefined interfacial area between the two chromophores. Low efficiency of the "inward" energy transfer from "outer" PPP to the "inner" PT chromophore could be related to blocking the energy transfer toward the "inner" PT chromophore by the exciplex-forming interfacial layer and not by the effect of spatial nanoscale confinement. Importantly, the $\mathrm{SiO}_{2} @ \mathrm{PT}-b$-PPP hybrid nanoparticles with their sharp interfacial border between the PT and PPP sublayers represent a first example of controlled preparation of core-shell nanoparticles with well-defined block copolymer shell.

\section{Conclusions}


Surface-initiated controlled chain-growth Kumada catalyst-transfer polymerization is an efficient way to prepare hybrid core-shell nanoparticles consisting of conjugated polymer shell attached to the central $\mathrm{SiO}_{2}$ core. This process offers a platform for engineering nanoparticles with a homopolymer (PT or PPP) shell as well as for nanoparticles with a structurally well-defined block copolymer shell. The resulting hybrid core-shell nanoparticles were exceptionally stable and showed unique spectroscopic features associated with both the effect of nanoscale morphology and specific molecular organization of the polymer chains in the CP shell. Most interesting was the effect of the order of CP chromophores on the intra-particle energy transfer between PPP and PT chromophores in block copolymer shells showing strong dependence on the "inner" vs. "outer" placement of the polymer chromophores. These findings provide prospects for fine-tuning of photophysical characteristics of hybrid core-shell nanoparticles, especially for the applications in optoelectronic devices, biomarkers and contrast agents, as well as chemo- and biosensors.

Supporting Information Available. Detailed synthetic and experimental procedures, and additional data and figures. This material is available free of charge via the Internet at http://pubs.acs.org.

\section{Corresponding Author}

E-mail: een@1su.edu (E.E.N.).

\section{Notes}

The authors declare no competing financial interest.

Acknowledgements. This research was supported by the U.S. Department of Energy under EPSCoR Grant No. DE-SC0012432 with additional support from the Louisiana Board of Regents. The initial experimental studies were supported by the National Science Foundation (grant DMR-1006336). C.R. acknowledges the Hightower Family Fund (School of Materials Science and Engineering, Georgia Tech). Kind appreciation is due to Ying Xiao (LSU Shared Instrumentation Facility) and Dr. Jibao He 
(Tulane University Coordinated Instrumentation Facility) for help with electron microscopy imaging, and Dr. Rafael Cueto (LSU Chemistry Department) for helping with TGA experiments. We also acknowledge Carrie Gao for general help with EQ-SANS beamline at the Oak Ridge National Laboratory. The Research at Oak Ridge National Laboratory's Spallation Neutron Source and Center for Nanophase Materials Sciences was sponsored by the Scientific User Facilities Division, Office of Basic Energy Sciences, U.S. Department of Energy.

\section{References and Notes:}

(1) Wang, J. Nanomaterial-based electrochemical biosensors. Analyst 2005, 130, 421-426.

(2) Darbha, G. K.; Ray, A.; Ray, P. C. Gold nanoparticle-based miniaturized nanomaterial surface energy transfer probe for rapid and ultrasensitive detection of mercury in soil, water, and fish. ACS Nano 2007, 1, 208-214.

(3) Shi, J.; Zhu, Y.; Zhang, X.; Baeyens, W. R. G.; García-Campaña, A. M. Recent developments in nanomaterial optical sensors. TrAC, Tends Anal. Chem. 2004, 23, 351-360.

(4) Rowland, C. E.; Brown III, C. W.; Delehanty, J. B.; Medintz, I. L. Nanomaterial-based sensors for the detection of biological threat agents. Mater. Today 2016, 19, 464-477.

(5) Landi, B. J.; Castro, S. L.; Ruf, H. J.; Evans, C. M.; Bailey, S. G.; Raffaelle, R. P. CdSe quantum dot-single wall carbon nanotube complexes for polymeric solar cells. Sol. Energy Mater. Sol. Cells 2005, $87,733-746$.

(6) Hammer, N. I.; Emrick, T.; Barnes, M. D. Quantum dots coordinated with conjugated organic ligands: new nanomaterials with novel photophysics. Nanoscale Res. Lett. 2007, 2, 282-290. 
(7) Jariwala, D.; Sangwan, V. K.; Lauhon, L. J.; Marks, T. J.; Hersam, M. C. Carbon nanomaterials for electronics, optoelectronics, photovoltaics, and sensing. Chem. Soc. Rev. 2013, 42, 2824-2860.

(8) Pramanik, M.; Patra, A. K.; Bhaumik, A. Self-assembled titanium phosphonate nanomaterial having a mesoscopic void space and its optoelectronic application. Dalton Trans. 2013, 42, 5140-5149.

(9) Ray, P. C.; Khan, S. A.; Singh, A. K.; Senapati, D.; Fan, Z. Nanomaterials for targeted detection and photothermal killing of bacteria. Chem. Soc. Rev. 2012, 41, 3193-3209.

(10) Bartelmess, J.; Quinn, S. J.; Giordani, S. Carbon nanomaterials: multi-functional agents for biomedical fluorescence and Raman imaging. Chem. Soc. Rev. 2015, 44, 4672-4698.

(11) Byrappa, K.; Ohara, S.; Adschiri, T. Nanoparticle synthesis using supercritical fluid technology towards biomedical applications. Adv. Drug Deliv. Rev. 2008, 60, 299-327.

(12) Jung, J. H.; Yoon, M. J.; Lim, J. W.; Lee, Y. H.; Lee, K. E.; Kim, D. H.; Oh, J. H. Highperformance UV-vis-NIR phototransistors based on single-crystalline organic semiconductor gold hybrid nanomaterials. Adv. Funct. Mater. 2017, 27, 1604528.

(13) Chen, Y.; Shi, J. Chemistry of mesoporous organosilica in nanotechnology: molecularly organicinorganic hybridization into frameworks. Adv. Mater. 2016, 28, 3235-3272.

(14) Zhang, Q.; Wang, C.-F.; Ling, L.-T.; Chen, S. Fluorescent nanomaterial-derived white lightemitting diodes: what's going on? J. Mater. Chem. C 2014, 2, 4358-4373.

(15) Su, X.; Zhang, J.; Sun, L.; Koo, T.-W.; Chan, S.; Sundararajan, N.; Yamakawa, M.; Berlin, A. A. Composite organic-inorganic nanoparticles (COINs) with chemically encoded optical signatures. Nano Lett. 2005, 5, 49-54. 
(16) Bajaj, A.; Miranda, O. R.; Kim, I.-B.; Phillips, R. L.; Jerry, D. J.; Bunz, U. H. F.; Rotello, V. M. Detection and differentiation of normal, cancerous, and metastatic cells using nanoparticle-polymer sensor array. Proc. Natl. Acad. Sci. U. S. A. 2009, 106, 10912-10916.

(17) Kwong, C. Y.; Choy, W. C. H.; Djurišić, A. B.; Chui, P. C.; Cheng, K. W.; Chan, W. K. Poly(3hexylthiophene): $\mathrm{TiO}_{2}$ nanocomposites for solar cell applications. Nanotechnology 2004, 15, 11561161.

(18) Sih, B. C.; Wolf, M. O. Metal nanoparticle - conjugated polymer nanocomposites. Chem. Commun. 2005, 3375-3384.

(19) Liang, Z.; Dzienis, K. L.; Xu, J.; Wang, Q. Covalent layer-by-layer assembly of conjugated polymers and CdSe nanoparticles: multilayer structure and photovoltaic properties. Adv. Funct. Mater. 2006, 16, 542-548.

(20) Islam, M. A.; Purkait, T. K.; Mobarok, M. H.; Hoehlein, I. M. D.; Sinelnikov, R.; Iqbal, M.; Azulay, D.; Balberg, I.; Millo, O.; Rieger, B.; Veinot, J. G. C. Grafting poly(3-hexylthiophene) from silicon nanocrystal surfaces: synthesis and properties of a functional hybrid material with direct interfacial contact. Angew. Chem. Int. Ed. 2016, 55, 7393-7397.

(21) Awada, H.; Bousquet, A.; Dagron-Lartigau, C.; Billon, L. Surface-initiated polymerization of AA/B-B type conjugated monomers by palladium-catalyzed Stille polycondensation: towards low band gap polymer brushes. $R S C A d v$. 2015, 5, 78436-78440.

(22) Zhao, L.; Lin, Z. Crafting semiconductor organic-inorganic nanocomposites via placing conjugated polymers in intimate contact with nanocrystals for hybrid solar cells. Adv. Mater. 2012, 24, 4353-4368. 
(23) Bousquet, A.; Awada, H.; Hiorns, R. C.; Dagron-Lartigau, C.; Billon, L. Conjugated-polymer grafting on inorganic and organic substrates: a new trend in organic electronic materials. Prog. Polym. Sci. 2014, 39, 1847-1877.

(24) Marshall, N.; Sontag, S. K.; Locklin, J. Surface-initiated polymerization of conjugated polymers. Chem. Commun. 2011, 47, 5681-5689.

(25) Xu, J.; Wang, J.; Mitchell, M.; Mukherjee, P.; Jeffries-EL, M.; Petrich, J. W.; Lin, Z. Organicinorganic nanocomposites via directly grafting conjugated polymers onto quantum dots. $\mathrm{J}$. Am. Chem. Soc. 2007, 129, 12828-12833.

(26) Stalder, R.; Xie, D.; Zhou, R.; Xue, J.; Reynolds, J. R.; Schanze, K. S. Variable-gap conjugated oligomers grafted to CdSe nanocrystals. Chem. Mater. 2012, 24, 3143-3152.

(27) Kanelidis, I.; Vaneski, A.; Lenkeit, D.; Pelz, S.; Elsner, V.; Stewart, R. M.; Rodríguez-Fernández, J.; Lutich, A. A.; Susha, A. S.; Theissmann, R.; Adamczyk, S.; Rogach, A. L.; Holder, E. Inorganicorganic nanocomposites of CdSe nanocrystals surface-modified with oligo- and poly(fluorene) moieties. J. Mater. Chem. 2011, 21, 2656-2662.

(28) Goodman, M. D.; Xu, J.; Wang, J.; Lin, Z. Semiconductor conjugated polymer-quantum dot nanocomposites at the air-water interface and their photovoltaic performance. Chem. Mater. 2009, $21,934-938$.

(29) de Roo, T.; Haase, J.; Keller, J.; Hinz, C.; Schmid, M.; Seletskiy, D. V.; Cölfen, H.; Leitenstorfer, A.; Mecking, S. A direct approach to organic/inorganic semiconductor hybrid particles via functionalized polyfluorene ligands. Adv. Funct. Mater. 2014, 24, 2714-2719.

(30) Awada, H.; Medlej, H.; Blanc, S.; Delville, M.-H.; Hiorns, R. C.; Bousquet, A.; Dagron-Lartigau, C.; Billon, L. Versatile functional poly(3-hexylthiophene) for hybrid particles synthesis by the 
grafting onto technique: core@shell ZnO nanorods. J. Polym. Sci., Part A: Poly. Chem. 2014, 52, $30-38$.

(31) Zotti, G.; Vercelli, B.; Berlin, A. Monolayers and multilayers of conjugated polymers as nanosized electronic components. Acc. Chem. Res. 2008, 41, 1098-1109.

(32) Moran, I. W.; Jhaveri, S. B.; Carter, K. R. Patterned layers of a semiconducting polymer via imprinting and microwave-assisted grafting. Small 2008, 4, 1176-1182.

(33) Zhang, Y.; Wang, C.; Rothberg, L.; Ng, M.-K. Surface-initiated growth of conjugated polymers for functionalization of electronically active nanoporous networks: synthesis, structure and optical properties. J. Mater. Chem. 2006, 16, 3721-3725.

(34) Ogawa, K.; Chemburu, S.; Lopez, G. P.; Whitten, D. G.; Schanze, K. S. Conjugated polyelectrolyte-grafted silica microspheres. Langmuir 2007, 23, 4541-4548.

(35) Skaff, H.; Emrick, T. Quantum dots tailored with poly(para-phenylene vinylene). J. Am. Chem. Soc. 2004, 126, 11322-11325.

(36) Williams, P. E.; Jones, S. T.; Walsh, Z.; Appel, E. A.; Abo-Hamed, E. K.; Scherman, O. A. Synthesis of conducting polymer-metal nanoparticle hybrids exploiting RAFT polymerization. $A C S$ Macro Lett. 2015, 4, 255-259.

(37) Alonzi, M.; Lanari, D.; Marrocchi, A.; Petrucci, C.; Vaccaro, L. Synthesis of polymeric semiconductors by a surface-initiated approach. RCS Adv. 2013, 3, 23909-23923.

(38) Kang, S.; Ono, R. J.; Bielawski, C. W. Controlled catalyst-transfer polycondensation and surfaceinitiated polymerization of a $p$-phenyleneethynylene-based monomer. J. Am. Chem. Soc. 2013, 135, 4984-4987. 
(39) de Roo, T.; Huber, S.; Mecking, S. CdSe/CdS-conjugated polymer core-shell nanoparticles by a grafting-from approach. ACS Macro Lett. 2016, 5, 786-789.

(40) Sheina, E. E.; Liu, J.; Iovu, M. C.; Laird, D. W.; McCullough, R. D. Chain growth mechanism for regioregular nickel-initiated cross-coupling polymerizations. Macromolecules 2004, 37, 3526-3528.

(41) Iovu, M. C.; Sheina, E. E.; Gil, R. R.; McCullough, R. D. Experimental evidence for the quasi"living" nature of the Grignard metathesis (GRIM) for the synthesis of regioregular poly(3alkylthiophenes). Macromolecules 2005, 38, 8649-8656.

(42) Yokoyama, A.; Miyakoshi, R.; Yokozawa, T. Chain-growth polymerization for poly(3hexylthiophene) with a defined molecular weight and a low polydispersity. Macromolecules 2004, 37, 1169-1171.

(43) Miyakoshi, R.; Yokoyama, A.; Yokozawa, T. Catalyst-transfer polycondensation. Mechanism of Ni-catalyzed chain-growth polymerization leading to well-defined poly(3-hexylthiophene). J. Am. Chem. Soc. 2005, 127, 17542-17547.

(44) Senkovskyy, V.; Khanduyeva, N.; Komber, H.; Oertel, U.; Stamm, M.; Kuckling, D.; Kiriy, A. conductive polymer brushes of regioregular head-to-tail poly(3-alkylthiophenes) via catalyst transfer surface-initiated polycondensation. J. Am. Chem. Soc. 2007, 129, 6626-6632.

(45) Tkachov, R.; Senkovskyy, V.; Komber, H.; Sommer, J.-U.; Kiriy, A. Random catalyst walking along polymerized poly(3-hexylthiophene) chains in Kumada catalyst-transfer polycondensation. $J$. Am. Chem. Soc. 2010, 132, 7803-7810.

(46) Bronstein, H. A.; Luscombe, C. K. Externally initiated regioregular P3HT with controlled molecular weight and narrow polydispersity. J. Am. Chem. Soc. 2009, 131, 12894-12895. 
(47) Khanduyeva, N.; Senkovskyy, V.; Beryozkina, T.; Bocharova, V.; Simon, F.; Nitschke, M.; Stamm, M.; Crötzschel, R.; Kiriy, A. Grafting of poly(3-hexylthiophene) from poly(4bromostyrene) films by Kumada catalyst-transfer polycondensation: revealing of the composite films structure. Macromolecules 2008, 41, 7383-7389.

(48) Khanduyeva, N.; Senkovskyy, V.; Beryozkina, T.; Horecha, M.; Stamm, M.; Uhrich, C.; Riede, M.; Leo, K.; Kiriy, A. Surface engineering using Kumada catalyst-transfer polycondensation (KCTP): preparation and structuring of poly(3-hexylthiophene)-based graft copolymer brushes. $J$. Am. Chem. Soc. 2009, 131, 153-161.

(49) Senkovskyy, V.; Tkachov, R.; Beryozkina, T.; Komber, H.; Oertel, U.; Horecha, M.; Bocharova, V.; Stamm, M.; Gevorgyan, S. A.; Krebs, F. C.; Kiriy, A. "Hairy” poly(3-hexylthiophene) particles prepared via surface-initiated Kumada catalyst-transfer polycondensation. J. Am. Chem. Soc. 2009, $131,16445-16453$.

(50) Tkachov, R.; Senkovskyy, V.; Horecha, M.; Oertel, U.; Stamm, M.; Kiriy, A. Surface-initiated Kumada catalyst-transfer polycondensation of poly(9,9-dioctylfluorene) from organosilica particles: chain-confinement promoted $\beta$-phase formation. Chem. Commun. 2010, 46, 1425-1427.

(51) Sontag, S. K.; Sheppard, G. R.; Usselman, N. M.; Marshall, N.; Locklin, J. Surface-confined nickel-mediated cross-coupling reactions: characterization of initiator environment in Kumada catalyst-transfer polycondensation. Langmuir 2011, 27, 12033-12041.

(52) Yang, L.; Sontag, S. K.; LaJoie, T. W.; Li, W.; Huddleston, N. E.; Locklin, J.; You, W. Surfaceinitiated poly(3-methylthiophene) as a hole-transport layer for polymer solar cells with high performance. ACS Appl. Mater. Interfaces 2012, 4, 5069-5073.

(53) Marshall, N.; Sontag, S. K.; Locklin, J. Substituted poly(p-phenylene) thin films via surfaceinitiated Kumada-type catalyst transfer polycondensation. Macromolecules 2010, 43, 2137-2144. 
(54) Boon, F.; Moerman, D.; Laurencin, D.; Richeter, S.; Guari, Y.; Mehdi, A.; Dubois, P.; Lazzaroni, R.; Clément, S. Synthesis of $\mathrm{TiO}_{2}-$ poly(3-hexylthiophene) hybrid particles through surface-initiated Kumada catalyst-transfer polycondensation. Langmuir 2014, 30, 11340-11347.

(55) Chavez, C. A.; Choi, J.; Nesterov, E. E. One-step simple preparation of catalytic initiators for catalyst-transfer Kumada polymerization: synthesis of defect-free polythiophenes. Macromolecules 2014, 47, 506-516.

(56) Youm, S. G.; Hwang, E.; Chavez, C. A.; Li, X.; Chatterjee, S.; Lusker, K. L.; Lu, L.; Strzalka, J.; Ankner, J. F.; Losovyj, Y.; Garno, J. C.; Nesterov, E. E. Polythiophene thin films by surfaceinitiated polymerization: mechanistic and structural studies. Chem. Mater. 2016, 28, 4787-4804.

(57) Jiang, P.; Bertone, J. F.; Hwang, K. S.; Colvin, V. L. Single-crystal colloidal multilayers of controlled thickness. Chem. Mater. 1999, 11, 2132-2140.

(58) Labastide, J. A.; Baghgar, M.; Dujovne, I.; Yang, Y.; Dinsmore, A. D.; Sumpter, B. G.; Venkataraman, D.; Barnes, M. D. Polymer nanoparticle superlattices for organic photovoltaic applications. J. Phys. Chem. Lett. 2011, 2, 3085-3091.

(59) Stöber, W.; Fink, A.; Bohn, E. Controlled growth of monodisperse silica spheres in the micron size range. J. Colloid Interface Sci. 1968, 26, 62-69.

(60) Rosu, C.; Selcuk, S.; Soto-Cantu, E.; Russo, P. S. Progress in silica polypeptide composite colloidal hybrids: from silica cores to fuzzy shells. Colloid Polym. Sci. 2014, 292, 1009-1040.

(61) Chen, S. H. Small angle neutron scattering studies of the structure and interaction in micellar and microemulsion systems. Annu. Rev. Phys. Chem. 1986, 37, 351-399.

(62) Chu, B.; Liu, T. Characterization of nanoparticles by scattering techniques. J. Nanopart. Res. 2000, 2, 29-41. 
(63) Such analysis of the grafted polymer degree of polymerization and surface grafting density could be considered only a rough estimate, and used with some caution. Unfortunately, direct determination of the degree of polymerization after de-grafting the polymer from the surface (e.g. by dissolving $\mathrm{SiO}_{2}$ core in hydrofluoric acid) was impossible due to complete insolubility of unsubstituted PT and PPP polymers.

(64) Briseno, A. L.; Holcombe, T. W.; Boukai, A. I.; Garnett, E. C.; Shelton, S. W.; Fréchet, J. M. J.; Yang, P. Oligo- and polythiophene/ZnO hybrid nanowire solar cells. Nano Lett. 2010, 10, 334-340.

(65) Beljonne, D.; Pourtois, G.; Silva, C.; Hennebicq, E.; Hertz, L. M.; Friend, R. H.; Scholes, G. D.; Setayesh, S.; Müllen, K.; Brédas, J. L. Interchain vs. intrachain energy transfer in acceptor-capped conjugated polymers. Proc. Nat. Acad. Sci. USA 2002, 99, 10982-10987.

(66) Averbeke, B. V.; Beljonne, D.; Hennebicq, E. Energy transport along conjugated polymer chains: through-space or through bond? Adv. Funct. Mater. 2008, 18, 492-498.

(67) Averbeke, B. V.; Beljonne, D. Conformational effects on excitation transport along conjugated polymer chains. J. Phys. Chem. A 2009, 113, 2677-2682.

(68) Zimmerman, H. E.; Lapin, Y. A.; Nesterov, E. E.; Sereda, G. A. Rodlike molecules and singlet energy transfer. J. Org. Chem. 2000, 65, 7740-7746.

(69) Murphy, C. B.; Zhang, Y.; Troxler, T.; Ferry, V.; Martin, J.; Jones, W. E., Jr. Probing Förster and Dexter energy-transfer mechanisms in fluorescent conjugated polymer chemosensors. J. Phys. Chem. B 2004, 108, 1537-1543.

(70) List, E. J. W.; Leising, G. Excitation energy migration assisted processes in conjugated polymers. Synth. Met. 2004, 141, 211-218. 
(71) Nesterov, E. E.; Zhu, Z.; Swager, T. M. Conjugation enhancement of intramolecular exciton migration in poly(p-phenylene ethynylene)s. J. Am. Chem. Soc. 2005, 127, 10083-10088.

(72) Kim, Y.; Cook, S.; Tuladhar, S. M.; Choulis, S. A.; Nelson, J.; Durrant, J. R.; Bradley, D. D. C.; Giles, M.; McCulloch, I.; Ha, C.-S.; Ree, M. A Strong regioregularity effect in self-organizing conjugated polymer films and high-efficiency polythiophene:fullerene solar cells. Nat. Mater. 2006, 5, 197-203.

(73) Grenier, C. R. G.; Pisula, W.; Joncheray, T. J.; Müllen, K.; Reynolds, J. R. Regiosymmetric poly(dialkylphenylenedioxythiophene)s: electron-rich, stackable $\pi$-conjugated nanoribbons. Angew. Chem. Int. Ed. 2007, 46, 714-717.

(74) Kim, S.-S.; Na, S.-I.; Jo, J.; Tae, G.; Kim, D.-Y. Efficient polymer solar cells fabricated by simple brush painting. Adv. Mater. 2007, 19, 4410-4415.

(75) Martin, T. P.; Wise, A. J.; Busby, E.; Gao, J.; Roehling, J. D.; Ford, M. J.; Larsen, D. S.; Moulé, A. J.; Grey, J. K. Packing dependent electronic coupling in single poly(3-hexylthiophene) H- and Jaggregate nanofibers. J. Phys. Chem. B 2013, 117, 4478-4487.

(76) Niles, E. T.; Roehling, J. D.; Yamagata, H.; Wise, A. J.; Spano, F. C.; Moulé, A. J.; Grey, J. K. Jaggregate behavior in poly(3hexylthiophene) nanofibers. J. Phys. Chem. Lett. 2012, 3, 259-263.

(77) Scharsich, C.; Lohwasser, R. H.; Sommer, M.; Asawapirom, U.; Scherf, U.; Thelakkat, M.; Neher, D.; Köhler, A. Control of aggregate formation in poly(3-hexylthiophene) by solvent, molecular weight, and synthetic method. J. Polym. Sci., Part B: Polym. Phys. 2012, 50, 442-453.

(78) Spano, F. C. The spectral signatures of Frenkel polarons in H- and J-aggregates. Acc. Chem. Res. 2010, 43, 429-439. 
(79) Spano, F. C.; Silva, C. H- and J-aggregate behavior in polymeric semiconductors. Annu. Rev. Phys. Chem. 2014, 65, 477-500.

(80) Jenekhe, S. A.; Osahene, J. A. Excimers and exciplexes of conjugated polymers. Science 1994, $265,765-768$.

(81) Gebler, D. D.; Wang, Y. Z.; Blatchford, J. W.; Jessen, S. W.; Fu, D.-K.; Swager, T. M.; MacDiarmid, A. G.; Epstein, A. J. Exciplex emission in bilayer polymer light-emitting devices. Appl. Phys. Lett. 1997, 70, 1644-1646.

(82) Alam, M. M.; Jenekhe, S. A. Nanolayered heterojunctions of donor and acceptor conjugated polymers of interest in light emitting and photovoltaic devices: photoinduced electron transfer at polythiophene/polyquinoline interfaces. J. Phys. Chem. B 2001, 105, 2479-2482.

(83) Hwang, I.; Scholes, G. D. Electronic energy transfer and quantum-coherence in $\pi$-conjugated polymers. Chem. Mater. 2011, 23, 610-620.

(84) Banerji, N.; Cowan, S.; Vauthey, E.; Heeger, A. J. Ultrafast relaxation of the poly(3hexylthiophene) emission spectrum. J. Phys. Chem. C 2011, 115, 9726-9739.

(85) Karam, T. E.; Smith, H. T.; Haber, L. H. Enhanced photothermal effects and excited-state dynamics of plasmonic size-controlled gold-silver-gold core-shell-shell nanoparticles. J. Phys. Chem. C 2015, 119, 18573-18580.

(86) Karam, T. E.; Siraj, N.; Warner, I. M.; Haber, L. H. Anomalous size-dependent excited-state relaxation dynamics of NanoGUMBOS. J. Phys. Chem. C 2015, 119, 28206-28213.

(87) Busby, E.; Carroll, E. C.; Chinn, E. M.; Chang, L.; Moulé, A. J.; Larsen, D. S. Excited-state selftrapping and ground-state relaxation dynamics in poly(3-hexylthiophene) resolved with broadband pump-dump-probe spectroscopy. J. Phys. Chem. Lett. 2011, 2, 2746-2769. 
(88) Guo, J.; Ohkita, H.; Benten, H.; Ito, S. Near-IR femtosecond transient absorption spectroscopy of ultrafast polaron and triplet exciton formation in polythiophene films with different regioregularities. J. Am. Chem. Soc. 2009, 131, 16869-16880.

(89) Socci, E. P.; Farmer, B. L.; Adams, W. W. Molecular dynamics simulations of a poly $(p-$ phenylene) oligomer. J. Polym. Sci., Part B: Polym. Phys. 1993, 31, 1975-1982.

(90) Petekidis, G.; Vlassopoulos, D.; Galda, P.; Rehahn, M.; Ballauff, M. Determination of chain conformation of stiff polymers by depolarized Rayleigh scattering in solution. Macromolecules 1996, 29, 8948-8953. 
Table of Content Graphic

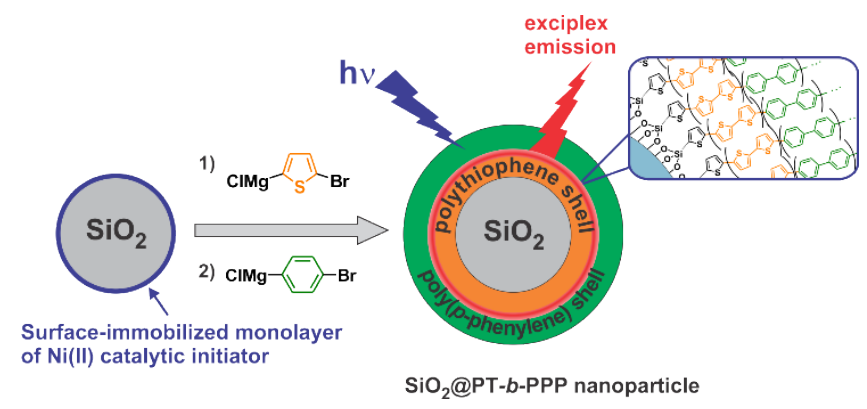

